\title{
A CRIAÇÃO DE MUNICÍPIOS APÓS A CONSTITUIÇÃO DE 1988*
}

\author{
Fabricio Ricardo de Limas Tomio
}

\section{Introdução}

O processo de redemocratização do Estado brasileiro, durante a década de 1980, transformou profundamente o ambiente político-institucional do país. Além da liberalização política, da ampliação da competição eleitoral e do incremento das liberdades civis - resultados de uma longa transição política com a paulatina adoção de mecanismos típicos de regimes democráticos - houve uma redefinição do papel institucional dos diver-

* Esta é uma versão modificada de um texto originalmente apresentado no II Encontro da ABCP (PUCSão Paulo, 20 a 24/11/2000). Agradeço as observações dos participantes do painel IP4 ("Federalismo, municipalização e poder local”), os comentários dos pareceristas anônimos da RBCS e, principalmente, a Argelina Figueiredo, por sua leitura detalhada e seus comentários esclarecedores. Inconsistências e desacertos são de minha inteira responsabilidade. sos níveis de poder. Essa reorientação da estrutura federativa brasileira favoreceu as unidades subnacionais, tanto pelo restabelecimento de competências usurpadas pelo regime ditatorial, quanto pela criação, sobretudo no caso dos municípios, de novos mecanismos de autonomia política.

O principal marco institucional dessa transformação política foi a promulgação da Constituição de 1988. A partir dela construiu-se todo um arcabouço jurídico que consolidou o novo arranjo democrático. A radicalidade destas transformações gerou um novo ordenamento federativo, isto é, os constituintes não só estabeleceram as bases do Estado democrático, como também instituíram um novo "pacto federativo".

A redefinição da competência política dos entes federativos notabilizou-se pela ampliação do escopo de atuação dos Estados e municípios, sendo que os últimos conquistaram a mais ampla autonomia política da história republicana. ${ }^{1}$ Ape- 
sar de ser mencionado como organização política autônoma em quase todas as constituições republicanas (exceto em 1937), somente em 1988 o município conquistou uma autonomia plena, obtendo, de fato, o status de ente federativo. Esta situação é extremamente peculiar, não sendo identificável em outros países com organização federativa. Na maioria das federações, ou, pelo menos, nos casos mais conhecidos, os municípios ou outros níveis de poder local são divisões administrativas das unidades federadas que delegam diferentes níveis de autonomia aos governos locais.

Outra mudança institucional que favoreceu a ampliação da autonomia política nas unidades subnacionais foi o novo arranjo tributário e fiscal. O processo de descentralização fiscal teve, todavia, início em meados dos anos de 1970, caminhando paralelamente à democratização. A promulgação da nova constituição somente consolidou a oferta de recursos fiscais e as competências tributárias de Estados e municípios.

A descentralização política e fiscal foi uma característica importante da redemocratização brasileira. Ela foi legitimada numa determinada cultura política, generalizada entre grupos políticos de diferentes matizes ideológicos, que associou democratização à descentralização, tratando estes dois termos quase como sinônimos. Os impactos, os limites e o encaminhamento desse processo num ambiente político democrático, apesar de não totalmente esclarecidos, têm sido objeto de estudo de diversos autores em diferentes especialidades das ciências sociais. ${ }^{2}$ Um dos aspectos desta nova institucionalidade, no entanto, tem recebido atenção marginal. Trata-se do processo de fragmentação dos municípios brasileiros. Algo que, entre 1988 e 2000, gerou 1438 novos municípios - 25\% de todos municípios existentes atualmente no Brasil.

$\mathrm{Na}$ literatura especificamente direcionada à temática, a abordagem desse fenômeno político tem sido guiada, geralmente, por orientações normativas. ${ }^{3}$ Em virtude disto, ela tende a concentrarse mais nos aspectos normativos e nas conseqüências do que na identificação das causas. As constatações mais comuns relacionam o desempenho, a proliferação e o fortalecimento dos governos locais, por um lado, ou o desequilíbrio fiscal, a dinâmica da divisão territorial sem planejamento e a fragilização das esferas superiores de governo, por outro, à vitalidade e à qualidade da democracia do país. Quando não foram simplesmente esquecidas, as explicações sobre as causas e as interpretações históricas desse processo político tornaram-se extremamente enviesadas.

Preencher parte dessa lacuna é o objetivo deste trabalho, por meio da identificação das causas e da descrição dos mecanismos que determinaram a dinâmica geral e a variação estadual no processo de emancipações municipais brasileiro. A abordagem do objeto privilegia, por um lado, a investigação do arranjo institucional responsável pela moldagem do ambiente que tornou possível as decisões políticas que geraram as emancipações municipais; e, por outro, a própria interação entre os atores políticos relevantes que produziu, por meio de processos decisórios relacionados, mas distintos, os dois principais resultados dessas decisões: a criação de novos municípios (por meio de leis ordinárias) e a transformação institucional na regulamentação das emancipações para facilitar ou dificultar as mesmas (a legislação complementar).

A elaboração da problemática relacionada às emancipações municipais tem uma fundamentação teórico-metodológica sustentada pelo individualismo metodológico e pelos modelos de abordagem neo-institucionalista, que privilegiam uma aproximação do fenômeno pela definição das instituições políticas como "regras do jogo", que moldam a interação estratégica e determinam as possíveis escolhas aos atores políticos que decidem a criação de um novo município. ${ }^{4}$

A análise limita-se a uma esfera específica de decisão política, o nível estadual, em que as regras e as decisões têm um efeito imediato sobre a emancipação de localidades. No entanto, para a compreensão histórica do processo, é interessante a incorporação de mecanismos institucionais dos outros níveis no modelo explicativo geral e a percepção da interação entre atores políticos das três esferas de poder (federal, estadual e municipal) na determinação do fenômeno político investigado.

O estudo comparativo do processo emancipacionista segue dois objetivos específicos: a 
identificação dos mecanismos institucionais, os quais, como variáveis independentes do processo, determinaram a configuração do ambiente de decisão política que, por um lado, gerou a "explosão municipal" contemporânea e, por outro, propiciou que esse fenômeno ocorresse de forma desigual nas diferentes unidades da federação; e a interpretação da lógica do processo de interação política, sobretudo os membros do executivo e do legislativo estaduais, determinando que decisões políticas favoráveis ou contrárias às emancipações fossem vitoriosas em cada Estado.

\section{Emancipações municipais nas décadas de 1980 e 1990}

Nas duas últimas décadas, foram criados milhares de municípios no Brasil, sendo que a grande maioria dessas emancipações ocorreu após a promulgação da Constituição de 1988. A intensa criação de municípios não é um fenômeno recente. Nos últimos cinqüenta anos, a quantidade de municípios foi quase quadruplicada. No entanto, apesar de constante, as emancipações não aconteceram num mesmo ritmo em todas as décadas. Como pode ser visto na Tabela 1, entre 1950 e 1970 a intensidade foi maior que no período atual, enquanto na década de 1970 o número de emancipações foi extremamente pequeno.

A sobreposição desses dados à história política contemporânea brasileira permite fazer uma associação direta entre regime político e criação de municípios. Ou seja, períodos democráticos, como a república populista (1945-1964), a nova república (anos de 1980) e o período atual, seriam caracterizados por uma descentralização política, institucional e fiscal que favoreceriam a maior intensidade de emancipações municipais. Ao contrário, períodos ditatoriais, como o regime militar (1964-1985), devido a suas características centralizadoras, inibiriam a criação de um grande número de municípios. Esse tipo de correlação é limitada por ser muito genérica e não apresentar os mecanismos políticos e institucionais específicos que agiram em cada regime político para a ocorrência das "ondas" ou "surtos" emancipacionistas. ${ }^{5}$

Há, sem dúvida, uma coincidência entre ritmo emancipacionista e regime político. A relação é correta quando identifica os períodos ditatoriais com a centralização político-administrativa. Seria inusitado se, no caso brasileiro, as ditaduras tivessem promovido o contrário, incorporando em sua agenda política a desconcentração fiscal e política. O principal equívoco está na transposição invertida da lógica política ditatorial para as situações democráticas. Nesse sentido, qualquer Estado democrático, incluindo o Brasil, apresentaria um único viés na repartição do "bolo" fiscal (em benefício das instâncias de poder local) e uma instabilidade intrínseca de sua organização político-administrativa e divisão territorial. Nenhuma dessas condições parece ser necessária, mas elas são contingentes a outros fatores políticos e institucionais mais específicos. Além disso, essa relação entre regime político e emancipações tem um sentido fatalista e é incapaz de explicar a diversidade do ritmo emancipacionista entre os Estados brasileiros.

Tabela 1

Quantidade de Municípios no Brasil - 1940/2000

\begin{tabular}{l|ccccccc}
\hline REGIÕES & \multicolumn{7}{|c}{ ANOS } \\
\hline \multirow{3}{*}{ Norte } & 1940 & 1950 & 1960 & 1970 & 1980 & 1990 & 2000 \\
\cline { 2 - 7 } Nordeste & 88 & 99 & 120 & 143 & 153 & 298 & 449 \\
Sudeste & 584 & 609 & 903 & 1376 & 1375 & 1509 & 1791 \\
Sul & 641 & 845 & 1085 & 1410 & 1410 & 1432 & 1668 \\
Centro-Oeste & 181 & 224 & 414 & 717 & 719 & 873 & 1189 \\
Total (Brasil) & 80 & 112 & 244 & 306 & 317 & 379 & 463 \\
\hline
\end{tabular}

Fonte: IBGE e TSE. 
A diferenciação no ritmo emancipacionista entre os Estados motivou outras explicações sobre o processo que são, muitas vezes, menos plausíveis do que a vinculação direta com o regime político. Essas tentativas de elucidar o problema são fundamentadas em vários aspectos do processo emancipacionista (causas societais e políticas) e variam muito quanto à abordagem teórico-epistemológica adotada. Porém, na maior parte dos casos, simplesmente não se sustentam diante de uma avaliação lógica ou de um teste empírico mais elaborado. ${ }^{6}$

A onda emancipacionista não foi um fenômeno totalmente nacional, mas concentrado em alguns Estados (ver Tabela 2). Em termos proporcionais, a maioria dos Estados das regiões Norte e
Centro-Oeste se destacam, mas, quantitativamente, as emancipações nessas regiões não são tão relevantes. O pequeno número de municípios em 1980, as características de fronteira e a criação de novos Estados devem ter, juntamente com as determinações institucionais, motivado o altíssimo índice relativo de emancipações nessas regiões.

Outra característica verificável é a similaridade no incremento relativo das emancipações que ocorreu em Estados com indicadores socioeconômicos absolutamente distintos: Rio Grande do Sul e Piauí dobraram a quantidade de municípios; o Maranhão apresentou um alto índice de emancipações; Santa Catarina, Espírito Santo e Rio de Janeiro ficaram um pouco acima da média brasileira. Os

Tabela 2

Quantidade, Incremento e População dos Municípios Criados (por Estados) - 1988/2000

\begin{tabular}{|c|c|c|c|c|c|c|c|c|c|c|c|c|}
\hline ESTADOS & \multicolumn{2}{|c|}{ MunicíPIOs } & \multicolumn{2}{|c|}{ INCREMENTO } & \multicolumn{8}{|c|}{ Municípios CRIados (por tamanho da população, em mil hab.) } \\
\hline & 1988 & 2000 & Total & $(\%)$ & & & & & & $\overline{10}$ & & \\
\hline RS & 244 & 497 & 253 & $104 \%$ & 207 & $82 \%$ & 38 & $15 \%$ & 8 & $3 \%$ & 253 & $100 \%$ \\
\hline TO & 6 & 139 & 133 & $2.217 \%$ & 83 & $62 \%$ & 33 & $25 \%$ & 17 & $13 \%$ & 133 & $100 \%$ \\
\hline MG & 722 & 853 & 131 & $18 \%$ & 65 & $50 \%$ & 55 & $42 \%$ & 11 & $8 \%$ & 131 & $100 \%$ \\
\hline PI & 116 & 222 & 106 & $91 \%$ & 76 & $72 \%$ & 27 & $25 \%$ & 3 & $3 \%$ & 106 & $100 \%$ \\
\hline SC & 199 & 293 & 94 & $47 \%$ & 71 & $76 \%$ & 19 & $20 \%$ & 4 & $4 \%$ & 94 & $100 \%$ \\
\hline PR & 311 & 399 & 88 & $28 \%$ & 45 & $51 \%$ & 32 & $36 \%$ & 11 & $13 \%$ & 88 & $100 \%$ \\
\hline MA & 132 & 217 & 85 & $64 \%$ & 12 & $14 \%$ & 38 & $45 \%$ & 35 & $41 \%$ & 85 & $100 \%$ \\
\hline SP & 572 & 645 & 73 & $13 \%$ & 51 & $70 \%$ & 12 & $16 \%$ & 10 & $14 \%$ & 73 & $100 \%$ \\
\hline GO & 181 & 246 & 65 & $36 \%$ & 50 & $77 \%$ & 6 & $9 \%$ & 9 & $14 \%$ & 65 & $100 \%$ \\
\hline MT & 82 & 139 & 57 & $70 \%$ & 37 & $65 \%$ & 12 & $21 \%$ & 8 & $14 \%$ & 57 & $100 \%$ \\
\hline PA & 87 & 143 & 56 & $64 \%$ & 4 & $7 \%$ & 11 & $20 \%$ & 41 & $73 \%$ & 56 & $100 \%$ \\
\hline $\mathrm{PB}$ & 171 & 223 & 52 & $30 \%$ & 28 & $54 \%$ & 11 & $21 \%$ & 13 & $25 \%$ & 52 & $100 \%$ \\
\hline BA & 367 & 417 & 50 & $14 \%$ & - & $0 \%$ & 12 & $24 \%$ & 38 & $76 \%$ & 50 & $100 \%$ \\
\hline $\mathrm{RO}$ & 18 & 52 & 34 & $189 \%$ & 7 & $21 \%$ & 16 & $47 \%$ & 11 & $32 \%$ & 34 & $100 \%$ \\
\hline CE & 152 & 184 & 32 & $21 \%$ & - & $0 \%$ & 7 & $22 \%$ & 25 & $78 \%$ & 32 & $100 \%$ \\
\hline RJ & 66 & 92 & 26 & $39 \%$ & - & $0 \%$ & 10 & $38 \%$ & 16 & $62 \%$ & 26 & $100 \%$ \\
\hline ES & 58 & 78 & 20 & $34 \%$ & - & $0 \%$ & 9 & $45 \%$ & 11 & $55 \%$ & 20 & $100 \%$ \\
\hline PE & 167 & 184 & 17 & $10 \%$ & - & $0 \%$ & 4 & $24 \%$ & 13 & $76 \%$ & 17 & $100 \%$ \\
\hline RN & 151 & 167 & 16 & $11 \%$ & 12 & $75 \%$ & 4 & $25 \%$ & - & $0 \%$ & 16 & $100 \%$ \\
\hline MS & 65 & 77 & 12 & $18 \%$ & 2 & $17 \%$ & 9 & $75 \%$ & 1 & $8 \%$ & 12 & $100 \%$ \\
\hline AP & 5 & 16 & 11 & $220 \%$ & 7 & $64 \%$ & 2 & $18 \%$ & 2 & $18 \%$ & 11 & $100 \%$ \\
\hline AC & 12 & 22 & 10 & $83 \%$ & 4 & $40 \%$ & 6 & $60 \%$ & - & $0 \%$ & 10 & $100 \%$ \\
\hline RR & 8 & 15 & 7 & $88 \%$ & 4 & $57 \%$ & 3 & $43 \%$ & - & $0 \%$ & 7 & $100 \%$ \\
\hline $\mathrm{AL}$ & 96 & 102 & 6 & $6 \%$ & - & $0 \%$ & 3 & $50 \%$ & 3 & $50 \%$ & 6 & $100 \%$ \\
\hline $\mathrm{AM}$ & 59 & 62 & 3 & $5 \%$ & - & $0 \%$ & - & $0 \%$ & 3 & $100 \%$ & 3 & $100 \%$ \\
\hline SE & 74 & 75 & 1 & $1 \%$ & - & $0 \%$ & 1 & $100 \%$ & - & $0 \%$ & 1 & $100 \%$ \\
\hline TOTAL & 4121 & 5559 & 1438 & $35 \%$ & 765 & $53 \%$ & 380 & $26 \%$ & 293 & $20 \%$ & 1438 & $100 \%$ \\
\hline
\end{tabular}

Fonte: IBGE. 
Estados com baixos índices também apresentaram a mesma discrepância socioeconômica - como, por exemplo, Sergipe e São Paulo. No geral, esses dados reforçam a objeção às hipóteses explicativas que se sustentam somente em aspectos sociais ou em algum tipo de teleologia funcionalista.

A descentralização política gerada pela Constituição de 1988 determinou a transferência da regulamentação das emancipações da União para os Estados. A autonomia institucional dos Estados, na elaboração da regulamentação e na decisão política, foi o fator preponderante para o ritmo diferenciado na criação de novos municípios. Antes de 1988, em virtude da legislação federal restritiva, havia poucos distritos legalmente emancipáveis fora das regiões de colonização do Norte e Centro-Oeste. Além disso, na segunda metade da década de 1980, devido ao que parece ter sido uma crise de legitimidade das instituições geradas no governo militar, muitos municípios foram criados desrespeitando a legislação vigente. A eficácia jurídica da Lei Complementar federal (LC) 01/67 só ficou caracterizada quando a emancipação de algum desses municípios foi objeto de disputa judicial. Nos casos em que o processo tramitou sem recurso judicial, os municípios foram criados. ${ }^{7}$

Um outro aspecto relevante é a maior freqüência de municípios criados com pequena população (cerca de $74 \%$ dos municípios criados e instalados nas últimas duas décadas têm menos de dez mil habitantes). Na região Sul, estes perfazem mais de $90 \%$ do total. A emancipação municipal recente é, fundamentalmente, uma questão que envolve os micro e pequenos municípios do interior. A diminuição das exigências à emancipação municipal pelas legislações estaduais, aliada a outros componentes institucionais, está diretamente relacionada à criação de municípios, visto que cerca de $75 \%$ destas novas entidades federativas não poderiam existir dentro do quadro legal anterior à última Constituição.

\section{Atores e estratégias no processo emancipacionista}

Para compreender o processo de decisão política envolvido nas emancipações municipais, identificarei algumas premissas a partir de breves esquemas ideais sobre as preferências, as escolhas e as estratégias dos atores diretamente envolvidos na criação dos municípios. O primeiro pressuposto geral, implícito nesse esquema interpretativo, sustenta que os atores: 1) são indivíduos conscientes de suas preferências e agem racionalmente (escolhem entre alternativas e definem suas estratégias na interação com outros atores em função de suas expectativas futuras) para que os resultados das decisões políticas atendam a seus interesses; 2) determinam a natureza de suas escolhas pela perspectiva de ganhos individuais (reeleição, maximização da oferta de recursos fiscais, ganhos pecuniários por esquemas fisiológicos, incremento e/ou melhora das políticas públicas, etc.) ${ }^{8}$ 3) e definem suas estratégias, em situações de interação, constrangidos pelas regras (instituições) e por suas expectativas quanto às escolhas dos outros atores políticos envolvidos no processo decisório.

O segundo pressuposto sugere que as instituições políticas determinam as escolhas individuais de duas formas: 1) as instituições constrangem as escolhas dos atores políticos, moldando suas estratégias como "regras do jogo" que arbitram sua interação com os outros atores que participam do processo decisório; 2) a própria dinâmica institucional determina não só as estratégias, mas também pode modificar as preferências e interesses dos atores políticos. Isto ocorreria por meio de um processo contínuo de retroalimentação. Isto é, a forma pela qual os atores políticos percebem, negativa ou positivamente, as conseqüências dos resultados políticos, e o papel regulatório das instituições interfere nos sucessivos processos decisórios e na transformação dos interesses dos atores.

Diversos atores de todos os níveis federativos (de presidentes e ministros de Estado a vereadores e eleitores de pequenas localidades interioranas) envolveram-se nas decisões políticas que geraram os novos municípios e as instituições que regulamentaram o processo legal das emancipações municipais. No entanto, a apreciação desses atores é restrita ao processo de decisão política estadual, pois é nesta esfera de governo que a decisão de criação de municípios é definida.

No processo decisório estadual, há quatro tipos de atores políticos que participam das deli- 
berações, com maior ou menor capacidade de determinar a emancipação municipal. Existem as lideranças políticas locais, indivíduos que residem na localidade e, na maior parte dos Estados, possuem a prerrogativa de iniciar o processo legal emancipacionista. Diante dos interesses em jogo (ampliação da oferta de recursos fiscais e atribuição de autonomia política na localidade emancipanda), ${ }^{9}$ a estratégia dessas lideranças em relação aos outros atores seria: a) com os eleitores locais, mobilizá-los para que cooperem, votando favoravelmente no plebiscito e auxiliando na pressão sobre a representação política; b) com os deputados estaduais: (i) quando não houver necessidade de subscrição de um deputado ao requerimento para realização do plebiscito e/ou ao projeto de lei de criação do município, pressão sobre os membros da assembléia para que votem favoravelmente, com ameaças de retaliação eleitoral; e (ii) quando a subscrição de um parlamentar for necessária, promessa de recompensa de votos ao deputado que apadrinhar a iniciativa emancipacionista. ${ }^{10}$

Depois, há os eleitores que se manifestam no plebiscito. Caso a emancipação atenda aos seus interesses, as estratégias na interação com outros atores seriam semelhantes às descritas para as lideranças locais.

Há também os deputados estaduais que, em virtude das regras instituídas, possuem vários instrumentos para controlar o processo legislativo das emancipações e, efetivamente, participam de todas as fases do processo, interagindo com os outros atores e detendo, formalmente, o direito de interromper a emancipação da localidade em qualquer momento do processo. Em cada manifestação do legislativo, a maioria dos deputados não teria interesses significativos envolvidos. Para essa maioria não haveria um interesse fundamental na aprovação ou reprovação da emancipação do município. Em virtude disto, parto do pressuposto que o principal interesse da maioria dos deputados é a continuidade de sua carreira política. Individualmente, cada deputado definiria sua estratégia e escolheria o que maximiza sua chance de reeleição parlamentar ou de ocupação de outros cargos políticos.
Além disso, como as decisões legislativas são coletivas, a escolha individual dos parlamentares estaduais dependeria, primordialmente, da interação com os seus pares e da possibilidade de a maioria (exigida em cada votação do processo) dos membros da assembléia ter, individualmente, a expectativa de que os benefícios superariam os custos políticos das escolhas realizadas. Como os interesses das lideranças locais e do eleitorado tendem a ser predominantemente favoráveis à emancipação, as estratégias individuais dos deputados estaduais dependeriam dos constrangimentos institucionais e da estratégia adotada pelo executivo estadual. Se o executivo for favorável ou indiferente às emancipações municipais, a principal estratégia individual dos deputados seria cooperar com as lideranças locais e votar favoravelmente à divisão municipal. Em função da perspectiva de ganhos de patronagem (inseridos em uma lógica clientelista eleitoral ${ }^{11}$ e/ou de construção de uma rede fisiológica com aliados políticos no novo município, ${ }^{12}$ haveria um reforço positivo às expectativas de futuro sucesso eleitoral. Caso não haja mecanismos que permitam vincular o parlamentar à emancipação (como a subscrição da lei), mesmo que os benefícios eleitorais futuros sejam marginais, o voto individual contrário à emancipação tenderia a gerar somente perdas para o parlamentar, pela expectativa de retaliações eleitorais que o mesmo teria na localidade emancipanda.

Por outro lado, a simples oposição do executivo estadual às emancipações não alteraria as estratégias dos legisladores. Somente quando existe uma sólida coalizão de governo (independentemente de ser programática ou fisiológica), com maioria absoluta dentro da assembléia, haveria espaço para uma terceira estratégia individual entre os parlamentares. Neste caso, os deputados tenderiam a cooperar com o executivo estadual, por compromissos partidários e/ou receio de perdas futuras (demissão de correligionários em cargos do governo, cancelamento de investimentos em sua base eleitoral, cortes no financiamento de suas campanhas eleitorais, ameaça de expulsão partidária, perda de votos entre eleitores que apóiam o programa governista etc.), a despeito da expectativa de retaliação eleitoral pelos eleitores da localidade emancipanda. 


\section{Figura 1}

\section{Forma da Interação entre os Atores Políticos no Processo Decisório Estadual}

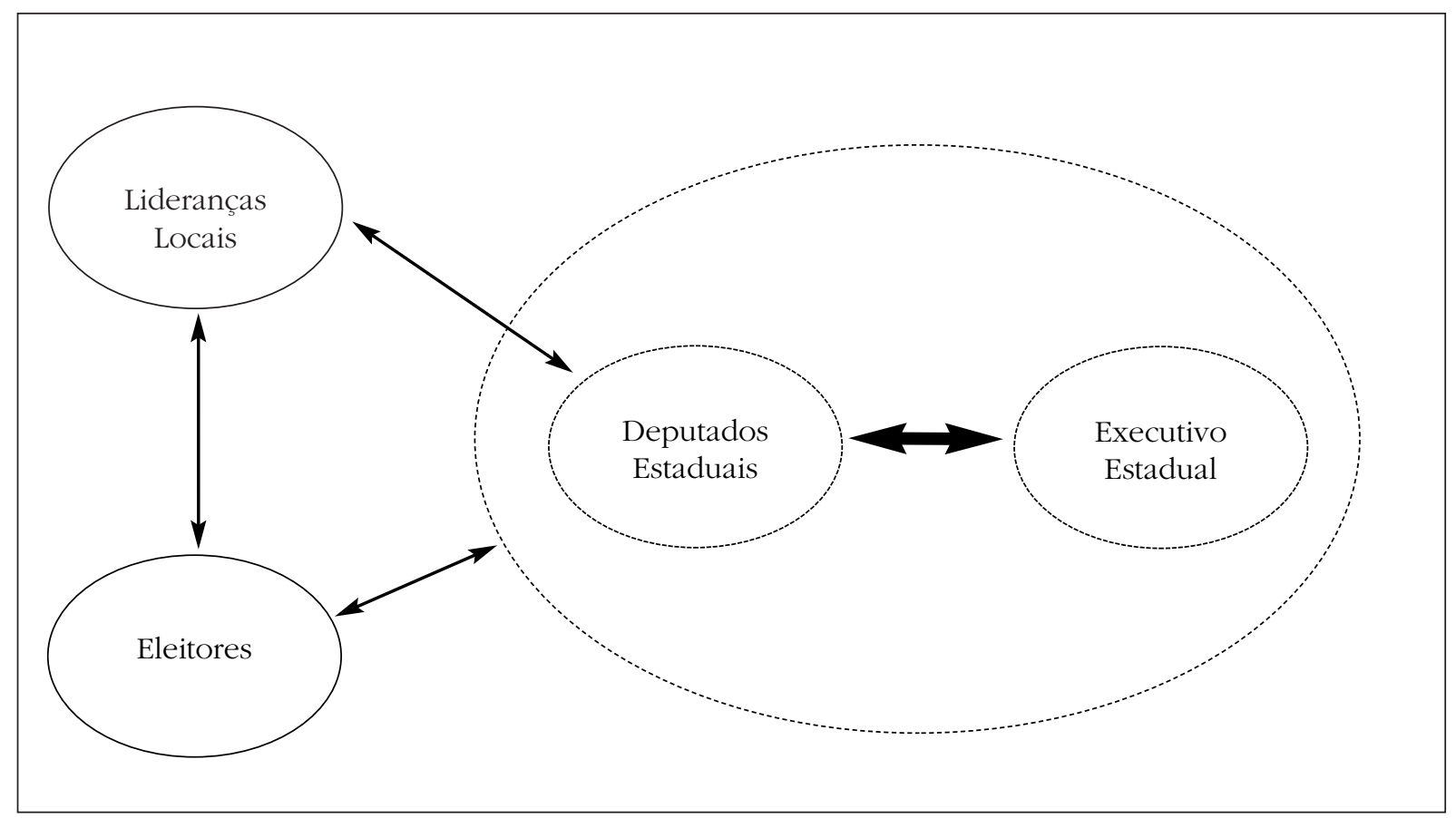

O quarto ator político, o executivo estadual, poderia expressar várias preferências. Todas consistentes dentro desta base dedutiva. O executivo poderia ser contrário, favorável ou indiferente em relação às emancipações, não havendo como determinar a priori o interesse dominante e qual escolha seria mais racional. Na interação com os eleitores e legisladores estaduais seria plausível que o governador viesse a apoiar as emancipações, primeiro, por motivações eleitorais, por exemplo, em Estados com eleitorado pouco extenso, quando essas envolvem parcela significativa do mesmo ou, ainda, quando houvesse expectativa de competição acirrada em eleições futuras em que a soma do eleitorado das localidades emancipandas tivesse um peso expressivo. Segundo, para manter maiorias fisiológicas no legislativo, em que o apoio à produção de leis clientelistas poderia beneficiar parlamentares da base governista. Terceiro, por razões político-ideológicas.

O executivo poderia também se opor às emancipações, tentando impedi-las através de ameaças de sanções diretamente sobre os deputados da base governista ou da utilização de seu direito de veto, exigindo que uma maioria absoluta fosse formada para que esse viesse a ser derrubado. Essa oposição poderia ocorrer por motivos pragmáticos, vinculados, por exemplo, a restrições de ordem orçamentária; ou por razões político-ideológicas, como princípios partidários e/ou programáticos do governo. O governante estadual também poderia ser, simplesmente, indiferente pelos mais variados motivos, não atuando nem favorável nem contrariamente à fragmentação territorial. Nesse caso, ou mesmo quando o governo fosse favorável, deveria ocorrer uma grande autonomia do poder legislativo, o que resultaria, provavelmente, em uma seqüência de decisões favoráveis às emancipações.

Todos os quatro tipos de atores participam do processo decisório sobre a criação de novos municípios. Sem a iniciativa das lideranças locais (nos casos em que esta é imprescindível ao processo legislativo) ou a votação plebiscitária, seria impossível haver divisão municipal. Porém, des- 
de que o processo tenha sido iniciado, o centro decisório é deslocado para o poder executivo e para os deputados estaduais, e o resultado depende das estratégias desenvolvidas por esses atores (Figura 1).

Portanto, caso os atores interajam conforme a racionalidade anteriormente descrita, com os deputados estaduais aprovando as emancipações, seria a variação na estratégia do executivo estadual e sua capacidade em implementá-la (medida pelo tamanho da coalizão governista, se majoritária ou minoritária), diante da mediação do arranjo institucional existente, que determina- ria a intensidade emancipacionista em cada Estado (Tabela 3).

Tabela 3

Resultado do Processo Legislativo da Emancipação Municipal

\begin{tabular}{l|l|cc}
\hline & \multicolumn{3}{|c}{$\begin{array}{c}\text { Posição do Executivo Estadual em } \\
\text { Relação à Emancipação }\end{array}$} \\
\hline & \multicolumn{3}{|c}{$\begin{array}{c}\text { Favorável ou } \\
\text { Indiferente }\end{array}$} \\
\hline $\begin{array}{l}\text { Tamanho } \\
\text { da Coalizão } \\
\text { Governista }\end{array}$ & Majoritária & Aprovação & Rejeição \\
& Minoritária & Aprovação & Aprovação \\
\hline
\end{tabular}

Figura 2

Processos de Criação de Municípios (emancipações)

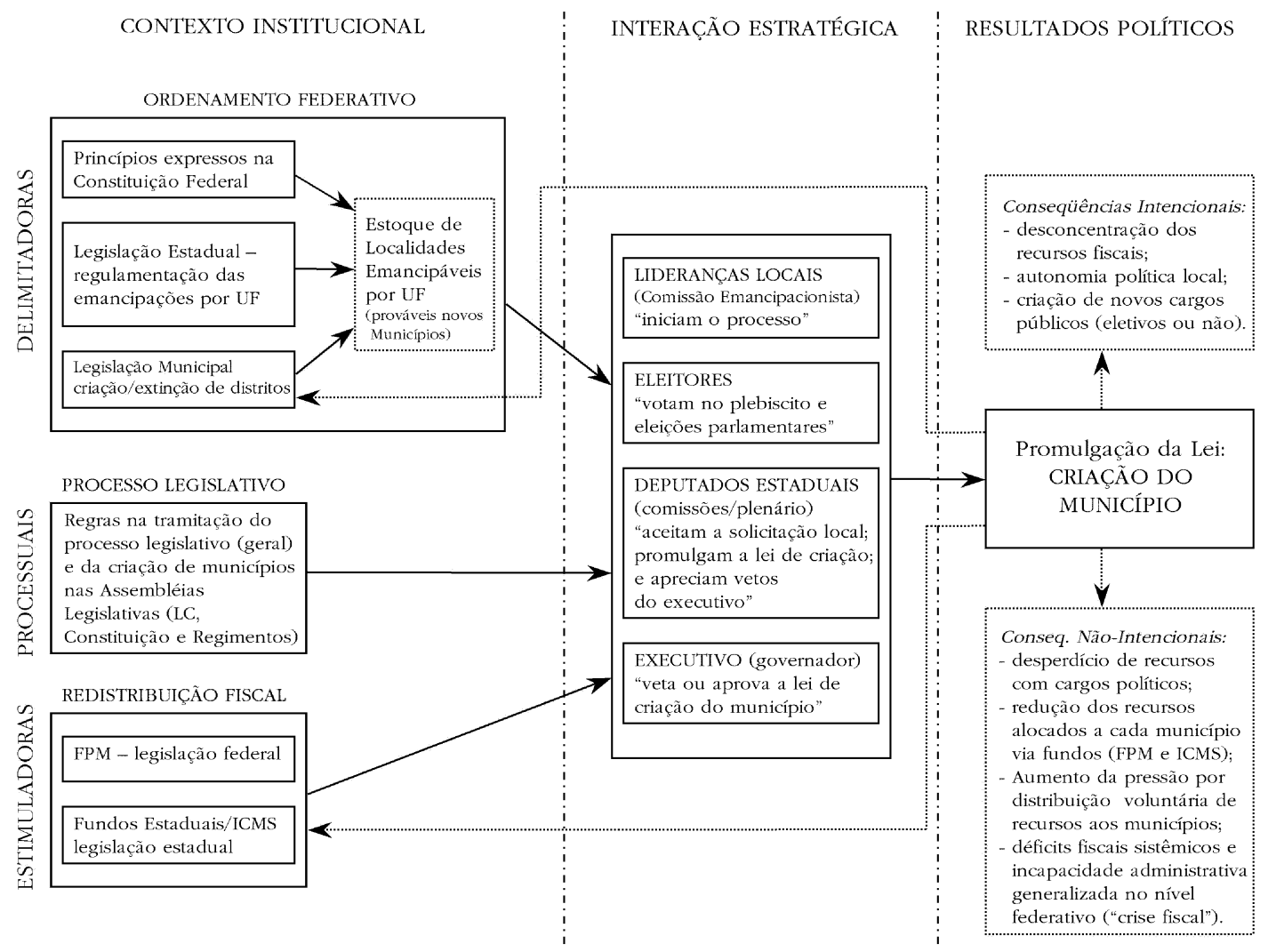




\section{Os mecanismos político-institucionais no processo emancipacionista}

A forma geral pela qual o contexto institucional determina o processo de emancipação e sua variação nos Estados pode ser visualizada na Figura 2. Nesse esquema, diferentes conjuntos de instituições têm papéis específicos na moldagem do ambiente em que ocorrem as decisões políticas que produziram as leis de criação dos municípios. A configuração histórica estabelecida, entre o arranjo institucional e as escolhas dos atores políticos, resultaria numa maior ou menor intensidade do fenômeno em cada unidade da federação.

Existem três tipos distintos de instituições presentes no processo emancipacionista: delimitadoras (federais, estaduais e municipais), definem o estoque de localidades emancipáveis, isto é, as localidades ou distritos passíveis de serem legalmente emancipados; estimuladoras (legislação que regulamenta a transferência de recursos aos municípios, o FPM e os fundos estaduais formados pelo ICMS), ampliam o interesse das lideranças políticas e do eleitorado das localidades em questão, sobretudo a partir da década de 1980, devido ao grande incremento das transferências de recursos fiscais aos municípios; e processuais (Constituição Federal, legislação federal e estadual e regimentos internos das assembléias legislativas), determinam a forma pela qual o processo legislativo deve seguir até a promulgação da lei e a possibilidade de interferência de cada ator político durante esse processo, "vetando" ou "alavancando" a criação dos municípios.

As instituições delimitadoras são as regras, contidas nos dispositivos constitucionais e nas leis complementares ou ordinárias, que estabelecem quais comunidades têm o direito de pleitear sua transformação em município. A relevância desse tipo de regra no jogo decisório é o seu caráter eminentemente restritivo, que determina o estoque de localidades emancipáveis em cada Estado e quem deverá se manifestar (plebiscito) para que ocorra a emancipação.

Nesse arranjo, o papel institucional de cada esfera federativa não é equivalente, havendo, inclusive, uma reorientação do centro decisório nas últimas duas décadas. A partir de 1988, as delimitações federais tiveram dois encaminhamentos completamente distintos. Inicialmente, seguindo uma tendência descentralizadora geral da redemocratização, havia somente duas restrições constitucionais: a preservação da "continuidade e unidade histórico-cultural do ambiente urbano" e a exigência da consulta plebiscitária às "populações diretamente interessadas" (Brasil, 1988, p. 21).

Em 1996, no que parece ter sido uma reação ao ritmo emancipacionista, o Congresso Nacional (por iniciativa do executivo federal) promulgou uma emenda à constituição (n. 15) que deu um novo caráter centralizador à matéria, limitando drasticamente a autonomia estadual recém-conquistada. A esfera federal retomou a prerrogativa de regulamentar o período hábil para a realização das emancipações. Além disso, a norma constitucional passou a exigir um "estudo de viabilidade" do novo município e, o ponto mais restritivo, a estender a consulta (plebiscito) ao eleitorado de todos os municípios envolvidos (Noronha, 1996, pp. 111-112).

Já o mecanismo delimitador da esfera municipal permaneceu inalterado durante todo o período. Aos municípios e seus governantes compete decidir, por meio de leis municipais, sobre a criação ou extinção de distritos em seu território. Este mecanismo é marginal no processo emancipacionista. Contudo, não é destituído de determinações, pelo menos nos Estados em que a regulamentação (lei complementar) somente admite a municipalização de distritos municipais.

O papel mais extenso e substancial sobre a regulamentação das emancipações coube, até 1996, à esfera estadual. ${ }^{13}$ A capacidade de legislar sobre a regulamentação das emancipações, por meio de leis complementares, foi um dos principais mecanismos que gerou as condições propícias para a recente onda emancipacionista e, em grande parte, determinou o seu ritmo diferenciado por Estado, sobretudo porque o caráter permissivo da maioria das regulamentações estaduais, quando comparadas à delimitação imposta pela LC federal 01/67, ampliou o estoque de localidades emancipáveis. 
De forma distinta, as instituições estimuladoras reúnem os mecanismos de repartição fiscal que proporcionam aos municípios um volume mínimo de recursos, independentemente de existir o fato gerador da receita no território desses mesmos municípios. Os recursos fiscais municipais têm origem em quatro fontes: 1) recursos de arrecadação própria, que são as taxas de serviços e os impostos de competência municipal, como o IPTU (predial e territorial), Imposto de Transmissão Inter Vivos e ISS (serviços); 2) recursos transferidos de impostos estaduais e federais em virtude da fonte de receita estar no território do município, que correspondem a alíquotas específicas desses impostos, como a tributação sobre atos e funcionários do poder municipal (100\%), o ITR (propriedade rural, 50\%), o IPVA (veículos, 50\%), o ICMS (mercadorias e serviços, 18,75\%) e parte que compete ao Estado como ressarcimento do IPI (produtos industrializados, 1,875\%) pela isenção de exportações; 3) recursos transferidos de fundos, que englobam impostos estaduais (ICMS) e federais (FPM), sem qualquer contrapartida na geração dos impostos; $;^{14}$ e 4) recursos de transferências voluntárias (convênios, obras etc.).

A maioria dos municípios criados nas últimas duas décadas depende diretamente das transferências federais para o seu funcionamento. A receita tributária própria é incapaz de sustentar sequer os cargos políticos gerados pela emancipação (prefeitos, vereadores, secretários municipais). ${ }^{15}$ Além disso, em geral, a atividade econômica nesses municípios é incipiente e sem fontes geradoras de impostos, tornando inexpressiva a participação direta nos tributos estaduais e federais. Portanto, é o FPM que garante a sobrevivência da maior parte das unidades emancipadas. Em virtude disso, somente o terceiro tipo de receita é considerado aqui um mecanismo institucional que estimula as emancipações municipais.

Entre os atores da localidade (lideranças e eleitorado), a garantia dos recursos provenientes do FPM é, provavelmente, uma das principais motivações às emancipações. Formado por uma parcela dos impostos federais (22,5\% do IPI e IR), desde a década de 1970, os recursos disponíveis a esse fundo vêm sendo incrementados, mais que quadruplicando entre 1975 e $1993 .{ }^{16}$ Do total do fundo, 10\% são destinados às capitais dos Estados, 3,6\% formam um fundo adicional para os municípios do interior com grande população (mais de 156.216 habitantes) e o restante, $86,4 \%$, é destinado a todos municípios do interior. ${ }^{17}$

A distribuição do fundo aos municípios do interior segue dois parâmetros. O primeiro é o populacional. Os municípios são divididos em dezoito faixas que recebem um coeficiente de participação. O menor coeficiente é 0,6, atribuído aos municípios com menos de 10.188 habitantes; o maior coeficiente é 4, para os municípios com população superior a 156.216 habitantes. ${ }^{18}$ Este era o único critério existente até 1990, o que igualava as transferências das cotas do FPM para todos municípios brasileiros de uma mesma faixa populacional.

Entretanto, a legislação que regulamenta a transferência do FPM foi alterada, certamente devido à concentração das emancipações em alguns Estados. Os congressistas modificaram os critérios de distribuição do FPM, criando índices de participação fixos por UF. ${ }^{19}$ Isso fechou o circuito de perdas e ganhos interestadual, gerado pelas ondas emancipacionistas da década de 1980. Na década seguinte, o jogo de soma zero (pela partilha do FPM através das emancipações) restringiu-se ao conjunto dos municípios de cada Estado.

Mesmo com a perspectiva de redução dos valores do FPM transferidos aos municípios, em Estados com grande número de emancipações, criar um novo município continua sendo um grande negócio para as pequenas localidades do interior. O fundo garante a fragmentação de pequenos municípios com pouca ou nenhuma perda para aquele que foi desmembrado, já que o ônus (o jogo de soma zero) distribui-se entre todos os municípios do Estado. Na maioria dos casos, os ganhos proporcionais (incremento do FPM per capita) geram pouca oposição da sede à emancipação, quando se pensa cada caso individualmente, porque só há benefícios aos atores municipais, tanto da localidade desmembrada quanto da sede municipal.

Finalmente, o terceiro conjunto de instituições (processuais) reúne os mecanismos endóge- 
nos ao funcionamento dos parlamentos estaduais e as regras que delimitam a interação entre os atores políticos no processo legislativo de criação de um novo município ou de alteração da regulamentação estadual sobre os critérios mínimos exigidos à emancipação. Esses mecanismos moldam a interação política, constrangendo as estratégias dos atores políticos nos diversos momentos de decisão até que a lei de emancipação ou a legislação complementar seja promulgada.

Alguns mecanismos processuais têm origem na Constituição e determinam tanto as linhas gerais do processo emancipacionista quanto as nor- mas básicas do funcionamento dos legislativos estaduais. Como esses dispositivos são constantes (a necessidade de maioria absoluta para a aprovação de leis complementares e derrubada de vetos ou maioria simples para leis ordinárias, o direito de veto total ou parcial do executivo estadual e a unicameralidade do poder legislativo estadual), não explicam as diferenças no ritmo e na intensidade da criação de municípios nem a dinâmica institucional nos Estados.

Existem também muitas características comuns no processo decisório estadual instituído pelas legislações complementares estaduais (Figu-

\section{Tabela 4}

Processo de Decisão Política

Instâncias e Oportunidades de Veto na Tramitação da Lei de Criação de Município

\begin{tabular}{|c|c|c|}
\hline INSTÂNCIAS DE VETO & OpORTUNidADES DE Veto $\left(^{*}\right)$ & $\begin{array}{l}\text { TENDÊNCIA DE O VETO OCORRER, } \\
\text { TENDO EM VISTA OS INTERESSES DOS ATORES }\end{array}$ \\
\hline \multirow[t]{5}{*}{ Legislativo Estadual } & $\begin{array}{l}\text { 1. Comissões (Especializada e/ouConstituição e Justiça) } \\
\text { apresentar parecer contrário ao pedido de plebiscito. }\end{array}$ & $\begin{array}{l}\text { Pouco Provável, só quando há oposição sistemática à } \\
\text { emancipação ou fidelidade a um executivo contrário. }\end{array}$ \\
\hline & 2. Plenário rejeitar pedido de plebiscito. & $\begin{array}{l}\text { Pouco Provável, só quando há oposição sistemática à } \\
\text { emancipação ou fidelidade a um executivo contrário. }\end{array}$ \\
\hline & $\begin{array}{l}\text { 4. Plenário não derrubar o Veto do Governador ao } \\
\text { plebiscito (quando esse é aprovado por lei). }\end{array}$ & $\begin{array}{l}\text { Pouco Provável, mas pode ocorrer devido à existência } \\
\text { de maioria governista sólida e comprometida progra- } \\
\text { mática ou fisiologicamente com o executivo. }\end{array}$ \\
\hline & 6. Plenário não aprovar a Lei de criação do município. & $\begin{array}{l}\text { Pouco Provável, após haver a aprovação popular em } \\
\text { plebiscito e devido aos interesses dos legisladores na } \\
\text { patronagem. }\end{array}$ \\
\hline & $\begin{array}{l}\text { 8. AL não derrubar o Veto do governador à Emanci- } \\
\text { pação. }\end{array}$ & $\begin{array}{l}\text { Extremamente Improvável, após a assembléia ter apro- } \\
\text { vado todo o processo, somente em casos atípicos. }\end{array}$ \\
\hline \multirow[t]{2}{*}{ Executivo Estadual } & $\begin{array}{l}\text { 3. Governador Vetar o plebiscito (quando esse é } \\
\text { aprovado por lei). }\end{array}$ & $\begin{array}{l}\text { Indeterminada, dado que há várias possibilidades ra- } \\
\text { zoáveis quanto aos interesses dos governadores nas } \\
\text { emancipações. }\end{array}$ \\
\hline & 7. Governador Vetar a lei de criação do município. & $\begin{array}{l}\text { Indeterminada, dado que há várias possibilidades ra- } \\
\text { zoáveis quanto aos interesses dos governadores nas } \\
\text { emancipações. }\end{array}$ \\
\hline \multirow[t]{2}{*}{ Instância Eleitoral } & $\begin{array}{l}\text { 5. Eleitores votando majoritariamente contra a eman- } \\
\text { cipação ou abstenção de mais de 50\% do eleitora- } \\
\text { do. }\end{array}$ & $\begin{array}{l}\text { Improvável, antes da emenda n. 15/1996, ocorrendo só } \\
\text { em casos excepcionais. } \\
\text { Muito Provável, após a emenda, com exceção das } \\
\text { emancipações em micromunicípios. }\end{array}$ \\
\hline & $\begin{array}{l}\text { 9. Futuras votações para o executivo e legislativo es- } \\
\text { tadual influenciando as decisões políticas. }\end{array}$ & $\begin{array}{l}\text { Provável somente para o legislativo, onde uma quanti- } \\
\text { dade pequena de votos pode definir a reeleição; no } \\
\text { caso do executivo parece desprezível, pelo menos em } \\
\text { Estados com eleitorado extenso. }\end{array}$ \\
\hline
\end{tabular}

Fonte: Legislação Complementar Estadual.

(*) As oportunidade de veto 3 e 4 só estão presentes nos Estados em que a lei complementar exige a aprovação da realização do plebiscito através de lei ordinária (somente no Rio Grande do Sul). Nos outros Estados, o plebiscito é aprovado por resolução ou decreto legislativo, não havendo oportunidade de veto do executivo. 
Figura 3

Fluxograma do Processo Decisório das Emancipações

(Oportunidades de Veto que as "Instituições" atribuem aos atores políticos)

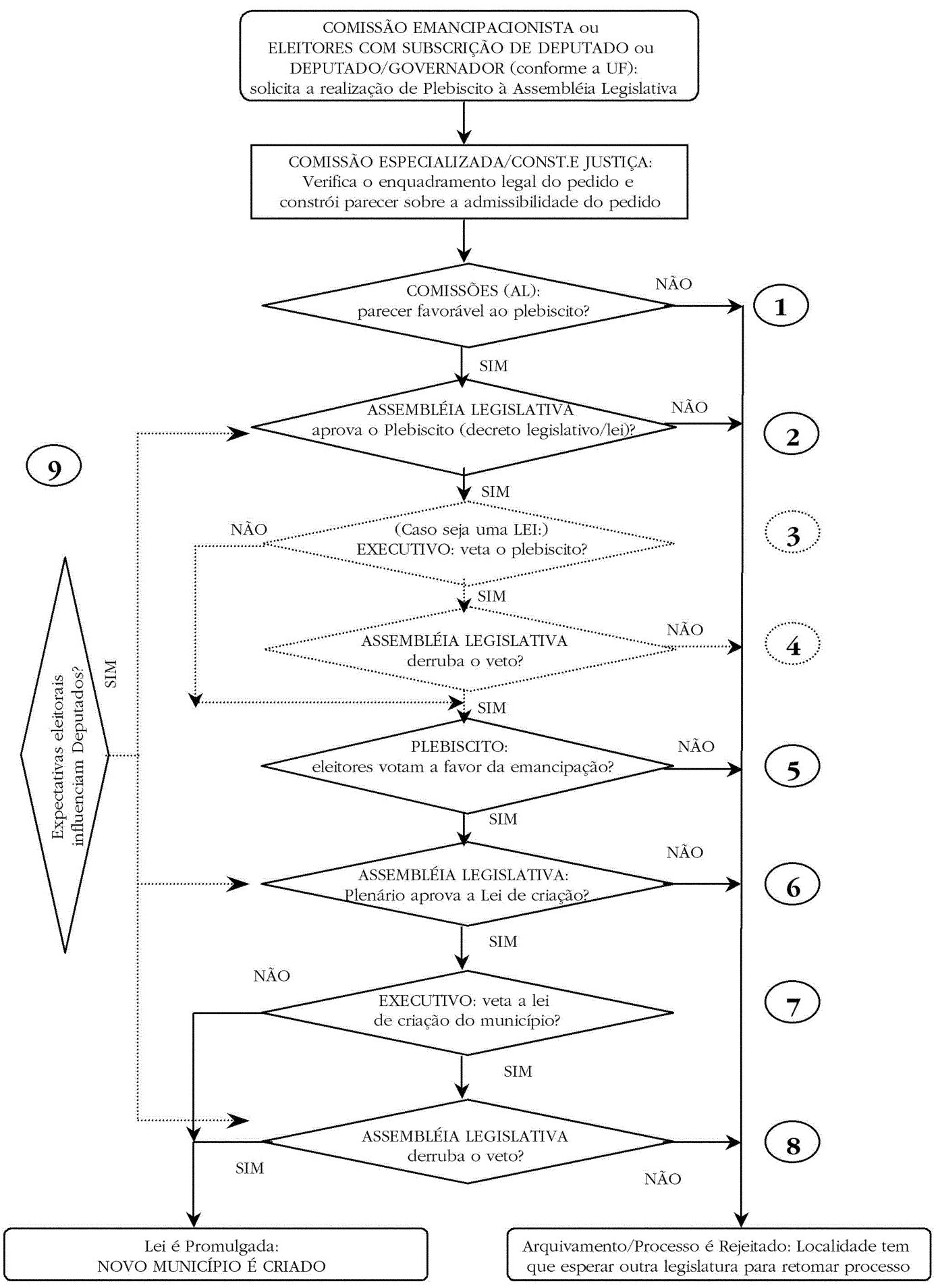


ra 3 e Tabela 4). A mais relevante é a disparidade de oportunidades de veto atribuída aos atores políticos. As prerrogativas dos deputados estaduais excedem a de todos os outros atores, maximizando, nas situações em que há convergência nas preferências da maioria dos parlamentares, a capacidade dos membros do poder legislativo implementar seus interesses.

Há, portanto, uma grande desvantagem institucional do executivo estadual. Como possui somente uma opção reativa (o veto), enquanto os deputados estaduais controlam todos os passos da tramitação, quando o executivo for contrário às emancipações necessitaria de uma maioria parlamentar governista sólida e confiável e de uma grande capacidade de controle externo sobre essa base de apoio para exercer suas preferências e reduzir a probabilidade de decisões favoráveis às emancipações. Já aos eleitores cabe apenas um veto direto (plebiscito) e outro vinculado às expectativas eleitorais dos deputados, sendo que a operação desse último maximizaria a autonomia do legislativo, pois favoreceria a consolidação de um tipo de clientelismo eleitoral com os deputados agindo como policy brokers.

Quando o executivo opõe-se às emancipações, a existência de uma maioria parlamentar governista é condição prévia para que essa escolha seja implementada pela Assembléia Legislativa. No entanto, não é suficiente. Maiorias não confiáveis e mecanismos processuais, cuja ocorrência nas leis complementares estaduais é variável, poderiam determinar uma autonomia, mesmo que pontual, do poder legislativo. A principal variável comparativa desse tipo encontra-se na iniciativa do processo legal das emancipações. Ao contrário de outras leis ordinárias, cuja iniciativa é estendida aos deputados, às comissões e ao executivo, algumas leis complementares estaduais atribuem aos atores locais a prerrogativa de iniciar o processo de criação dos municípios. Nesses casos, a proposição legislativa só iniciaria sua tramitação mediante a solicitação de um número mínimo de eleitores da localidade em questão. ${ }^{20}$

A oportunidade, ou mesmo a exigência, da subscrição parlamentar na lei de criação de municípios torna a mesma dependente, para sua apro- vação, da barganha alocativa entre os parlamentares (logrolling), dado que essa seria entendida, pelo parlamentar que tomou a iniciativa e por seus pares, como uma lei clientelista. Diante da oposição do executivo, com maioria governista, à emancipação, os custos de oportunidade política, tanto da apresentação da lei quanto da barganha com os outros deputados para sua aprovação, aumentariam a ponto de se tornarem proibitivos. Aprovar a lei nessa situação seria quase impossível, dado que o deputado teria de retribuir benefícios a seus pares que compensassem a provável retaliação do executivo. Além disso, a expectativa de retaliação, entre os deputados da base governista, inibiria inclusive a subscrição de leis de criação de municípios.

Por outro lado, quando a subscrição é proibida, tanto os custos da iniciativa e da barganha quanto a ameaça de retaliação sobre deputados individuais inexistem. Como os parlamentares não controlam a iniciativa e não podem se negar a receber os pedidos de emancipação, a quantidade destes dependerá das lideranças locais. Sua tramitação e aprovação no parlamento dependeriam do cálculo individual dos deputados sobre os benefícios eleitorais em apoiar o executivo ou as emancipações e do custo de possíveis retaliações do eleitorado local ou do executivo, que é zero para os parlamentares oposicionistas e pequeno, caso a maioria governista seja frágil, sobretudo se muitos desses deputados estiverem dispostos a não apoiar a posição do executivo. Desta forma, a proibição da iniciativa parlamentar constitui-se um mecanismo que limita as sanções do executivo e amplia a possibilidade de autonomia política do legislativo, principalmente quando a demanda por emancipações for suficiente para envolver os interesses de muitos parlamentares governistas.

\section{Definição das hipóteses e operacionaliza- ção das variáveis no estudo comparativo}

O arranjo institucional gerado pela Constituição de 1988, conforme visto, atribuiu um papel central ao poder legislativo estadual na decisão sobre as emancipações municipais, tanto pelo 
deslocamento da regulamentação à esfera estadual, quanto pelo domínio formal do processo decisório, devido às oportunidades de veto atribuídas aos deputados estaduais. Além disso, o processo emancipacionista estadual possui um escopo mais amplo do que apenas a decisão sobre as leis de emancipação. Este incorpora, da regulamentação estadual (institucionalização), a definição das exigências mínimas à criação de novos municípios e da forma pela qual deve tramitar o processo legislativo. Juntamente com o resultado da interação entre o legislativo e o executivo, a dinâmica dessas instituições delimitadoras e processuais determinam o ritmo e a intensidade emancipacionista nos Estados.

Essa dinâmica envolve também a continuidade dos eventos e das decisões que resultaram na criação de municípios e na alteração das regulamentações das emancipações. Como pode ser visto na Figura 4, os resultados políticos e suas conseqüências (intencionais ou não-intencionais) têm uma capacidade de retroalimentação sobre a definição/transformação dos interesses dos atores políticos e, portanto, sobre como novas escolhas serão tomadas em momentos subseqüentes.

Isto poderia ser exemplificado por mudanças de estratégia adotada pelo executivo. Conforme o raciocínio proposto anteriormente, o executivo não possuiria um interesse dominante logicamente dedutível, sendo, portanto, muito dependente de como suas expectativas são alteradas pelas conseqüências dos resultados políticos. Numa situação em que as conseqüências do processo forem muito incisivas, haveria inclusive a possibilidade de redefinição dos interesses e das estratégia de alguns parlamentares.

Portanto, decisões contraditórias, tomadas por um mesmo ator no curso do processo, não seriam, necessariamente, originadas pela falta de racionalidade desses atores ou da escolha entre múltiplas situações aceitáveis, mas, talvez, pelo estabelecimento de uma nova racionalidade que provocasse a mudança nas escolhas e estratégias adotadas. Isto permitiria a transformação, por vezes radical, de algumas instituições (regulamentações estaduais) sem que houvesse substituição dos atores ou mudanças na coalizão governista, o que também poderia ocorrer, obviamente, quando os resultados eleitorais alterassem os atores no processo decisório.

Dessa forma, o estudo comparativo do processo emancipacionista nos Estados - a explicação de suas causas, da variação em seu ritmo e intensidade e da dinâmica institucional - se faz por meio de um conjunto de hipóteses que relacionam as proposições sobre a racionalidade instrumental dos atores políticos, os mecanismos institucionais, os resultados eleitorais e o policy feedback. As duas primeiras hipóteses procuram determinar a variação do processo emancipacionista (Figura 5).

\section{Figura 4 \\ Processo de decisão política (mudanca institucional)}

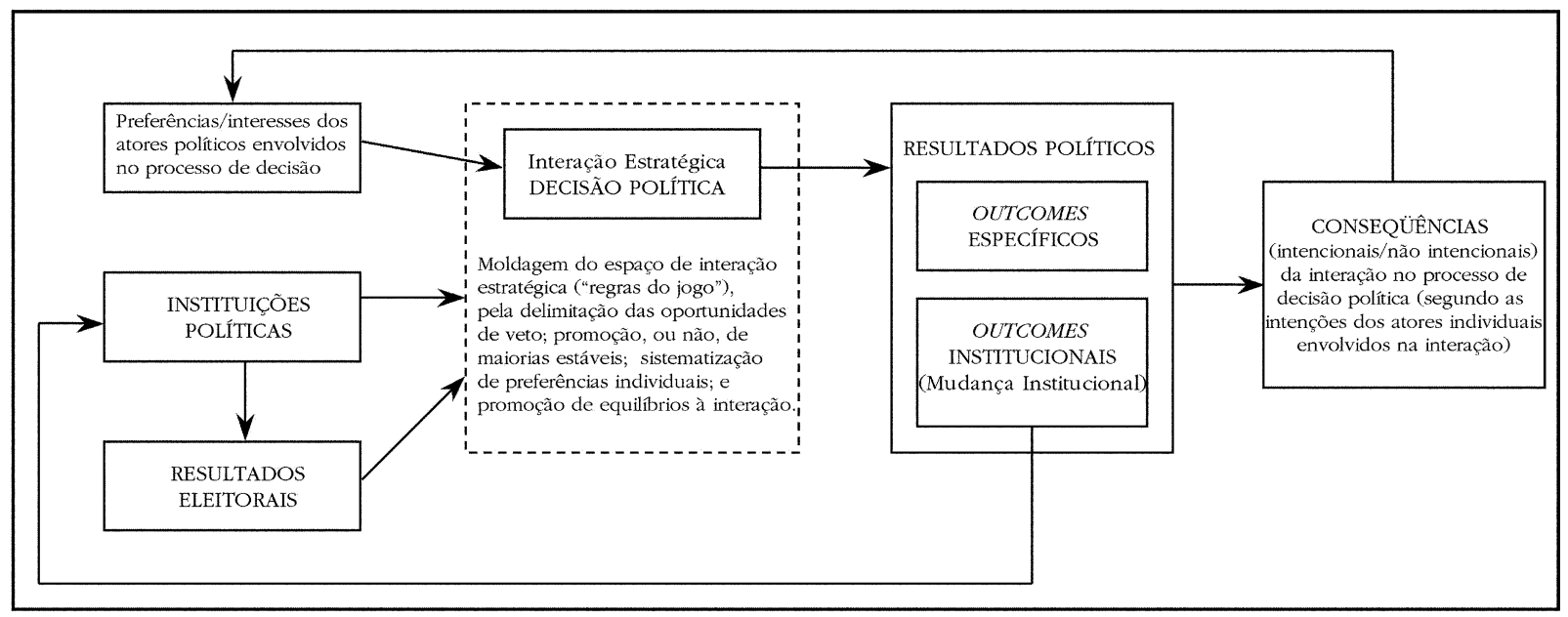


Figura 5 Hipótese (diagrama geral)

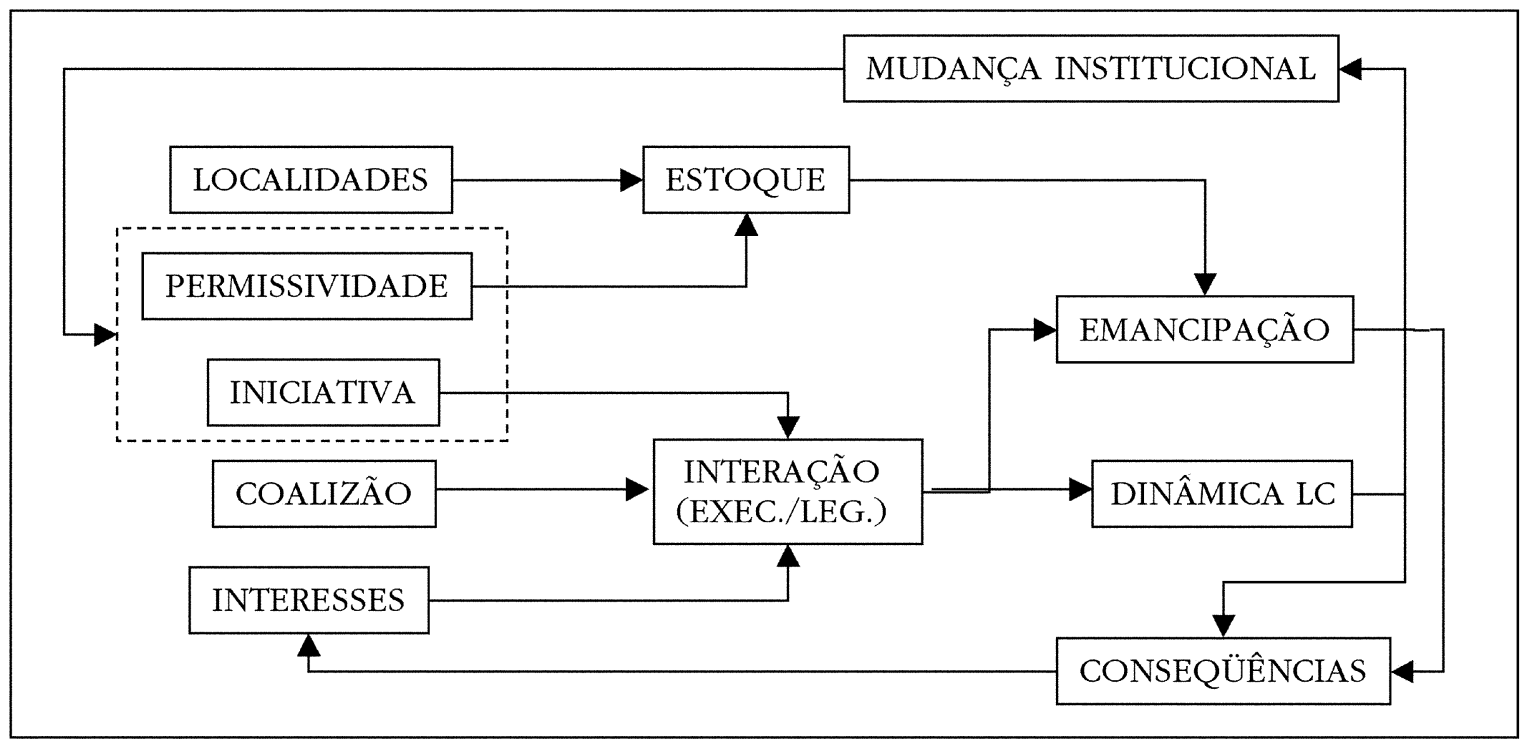

Quanto mais favorável for a posição estadual sobre as emancipações (resultante da relação de forças na interação executivo/legislativo) e quanto maior o estoque de localidades emancipáveis, maior a ocorrência relativa de emancipações municipais no Estado.

A institucionalização/alteração da regulamentação e o sentido desta (facilitar/dificultar as emancipações) dependerão da interação entre executivo e legislativo estadual e do tamanho/consistência da coalizão de governo existente no legislativo estadual (constituída pelos resultados eleitorais ou por alianças políticas posteriores): (a) quando for minoritária, a lei promulgada tenderia a facilitar as emancipações (comparada ao status quo); (b) quando for majoritária, com apoio vigoroso, o sentido da lei dependeria do interesse do executivo em facilitar/dificultar as emancipações; (c) quando for majoritária, com apoio frágil, o sentido da lei dependeria de barganhas pontuais entre o executivo e o legislativo.

As duas hipóteses seguintes especificam a determinação dos constrangimentos institucionais e históricos sobre as decisões políticas no processo emancipacionista e a disponibilidade de localidades emancipáveis, sendo que a primeira relaciona a variação das instituições às estratégias dos atores na interação executivo/legislativo e, em decorrência, à posição política estadual predominante sobre as emancipações.

A expectativa de autonomia do legislativo será maior quando as lideranças locais possuírem a exclusividade na iniciativa de criação de município e for minoritária ou majoritária, mas frágil, a coalizão governista na Assembléia Legislativa.

A extensão do estoque de localidades emancipáveis variará conforme a permissividade da regulamentação sobre as emancipações e a quantidade de localidades (distritos, vilas, lugarejos) não constituídas em município no Estado.

A últimas três hipóteses descrevem a determinação dos resultados eleitorais e das alianças políticas posteriores sobre as coalizões governistas, o feedback dos resultados políticos sobre as instituições e como as conseqüências do processo alteram as escolhas dos atores.

Quanto mais intensamente as conseqüências (intencionais/não intencionais) dos resultados das decisões políticas (emancipações e regulamentação) forem percebidas de forma negativa pelos atores políticos (principalmente o executivo), maior a probabilidade de que sejam contrários à criação de novos municípios. 
Quando os resultados das decisões políticas alterarem o contexto institucional das emancipações, poderão ocorrer mudanças no equilíbrio das relações de forças entre o executivo e o legislativo (posição favorável ou contrária às emancipações) devido à variação nos mecanismos institucionais que constrangem o processo de interação.

O tamanho e o tipo de coalizão de governo (apoio dos deputados estaduais ao executivo) serão determinados pelos resultados eleitorais e pelo momento de sua definição: (a) majoritária e vigorosa, quando a maioria absoluta dos membros do parlamento que apóia o executivo resulta de acordos partidários anteriores aos resultados eleitorais; (b) majoritária e frágil, quando a maioria absoluta é formada por alianças políticas posteriores à eleição; (c) minoritária, quando a maioria da assembléia não participa da coalizão de apoio ao executivo.

O teste empírico das hipóteses é realizado por meio de um conjunto de variáveis e indicadores da historicidade, dos resultados políticos, dos mecanismos institucionais e da motivação dos atores em relação às emancipações. A descrição das variáveis, os valores atribuídos e a caracterização de sua variação estão expostos na Tabela $5 .^{21}$

O valores são atribuídos de forma crescente (conforme a expectativa de aumento na intensidade do processo emancipacionista estadual): quanto mais baixo o valor atribuído às variáveis dependentes, menor a ocorrência dos resultados ou menos permissiva será a regulamentação criada ou a orientação de suas possíveis transformações posteriores; quanto mais baixo o valor atribuído às

Tabela 5

Atribuição de Valores às Variáveis do Processo Emancipacionista

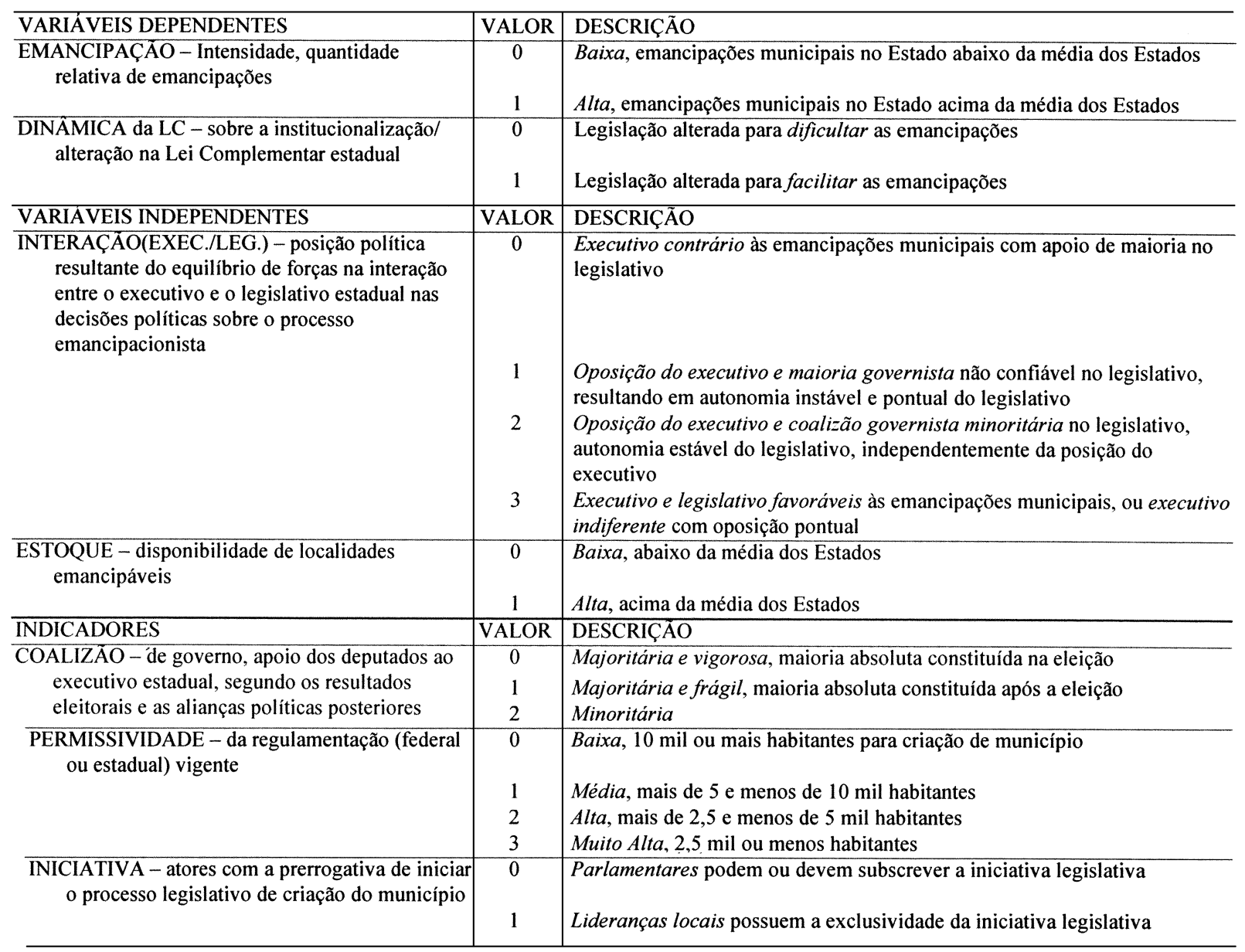




\section{Figura 6}

\section{Relação entre o Estoque (Distritos Emancipáveis) e as Emancipações (Valores Relativos)}

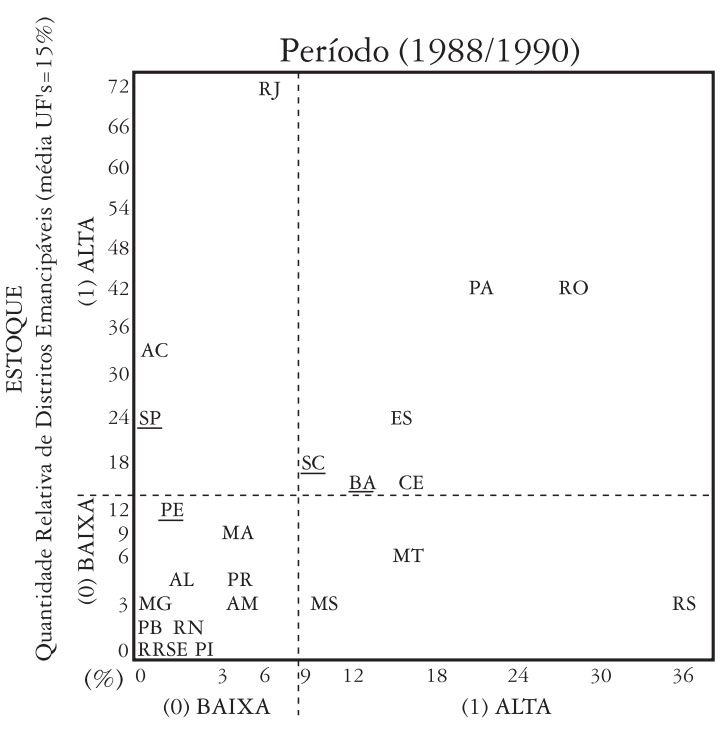

Quantidade Relativa de Emancipações (média UF's=8\%)

FONTE: IBGE e Legislação Federal e Estadual (*) Excluídos GO e TO, por causa da criacão de TO; e AP, por apresentar dados absurdamente discrepantes.

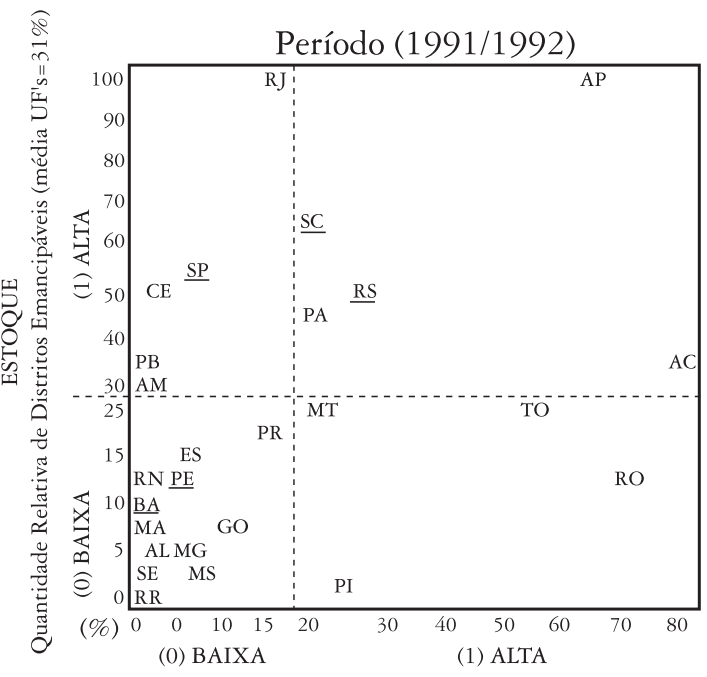

Quantidade Relativa de Emancipações (média UF's=18\%)

FONTE: IBGE e Legislação Estadual

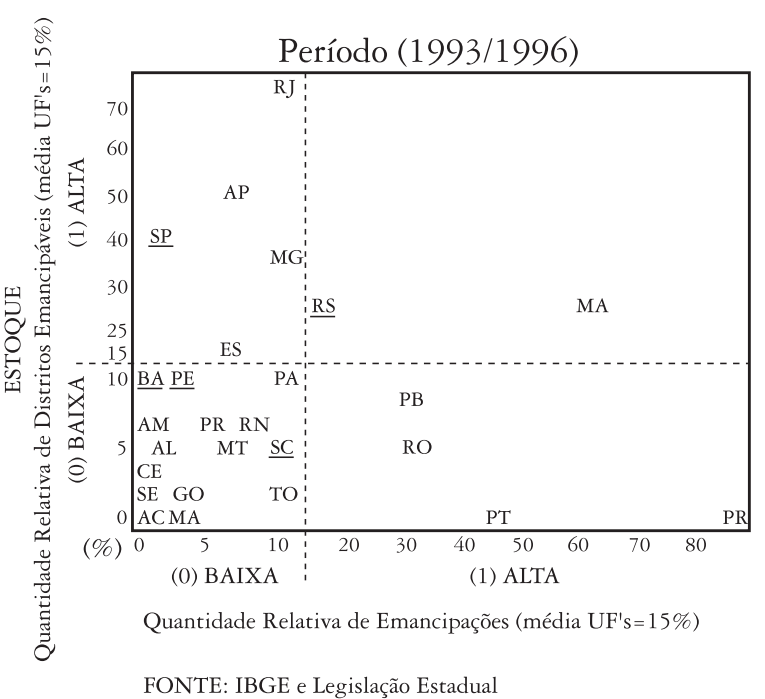

variáveis independentes e seus indicadores, menos provável será a ocorrência dos fenômenos descritos pelas variáveis dependentes. Portanto, as hipóteses terão maior validade explanatória quando, diante das evidências empíricas das unidades de comparação (Estados), mais freqüente for a variação no mesmo sentido entre as variáveis independentes e dependentes.

\section{Verificação das hipóteses}

A verificação das hipóteses será realizada em duas fases. Na primeira, com dados de todos os Estados brasileiros, é avaliada parcialmente a validade da primeira hipótese por meio da correlação entre o estoque de localidades emancipáveis e a intensidade das emancipações nos Estados. Somente na segunda fase, a partir de informações recolhidas em estudos de caso com uma amostra de cinco unidades da federação (Bahia, Pernambuco, Rio Grande do Sul, Santa Catarina e São Paulo), ${ }^{22}$ completa-se a avaliação da validade explanatória das 
quatro primeiras hipóteses apresentadas anteriormente. Em ambas, o processo emancipacionista brasileiro é separado em períodos, que correspondem aos anos em que houve criação de municípios - no momento seguinte à promulgação da Constituição (1988-1990) e nos anos que antecederam as eleições municipais (1991-1992 e 1993-1996).

A primeira hipótese afirma que deverá crescer a intensidade relativa de emancipações municipais quanto maior for a disponibilidade relativa de localidades emancipáveis e mais favorável for a posição política estadual resultante da interação entre o executivo e o legislativo estaduais. Isolando somente uma das variáveis independentes, a disponibilidade (estoque), ${ }^{23}$ é possível perceber que, apesar de seu potencial explicativo restrito (quando desassociada da interação entre executivo/legislativo), essa correlação não é espúria, dado que a maior parte dos surtos emancipacionistas estaduais se enquadra nas suas diretrizes (Figura 6).

No final da década de 1980, a maioria dos Estados não tinha editado suas leis complementares regulamentando as emancipações, o que manteve a validade da LC federal 01/67. Somente Santa Catarina, Ceará, Tocantins, Bahia, Rondônia e Acre editaram leis próprias nessa década, mas os três últimos definiram exigências semelhantes à legislação da ditadura militar, não ampliando seu estoque de distritos emancipáveis. Os dados discrepantes desse período, sem contar os Estados do Norte e Centro-Oeste, com suas características atípicas de fronteira de colonização, envolvem três Estados: Rio Grande do Sul, São Paulo e Rio de Janeiro. No primeiro, a lei federal foi simplesmente esquecida, isto é, no processo decisório estadual gaúcho dos anos de 1980, a delimitação do estoque emancipável não foi definida pelas regras (legado institucional do regime militar), mas somente pelos interesses dos atores (executivo, legislativo e lideranças locais). Portanto, os municípios foram criados sem a observância das restrições institucionais. Este fato, que explica a discrepância de sua classificação, também ocorreu em outros Estados, mas em nenhum caso com a intensidade verificada no Rio Grande do Sul.

Os outros dois Estados (São Paulo e Rio de Janeiro), que expressam em todos os períodos
(1990/1992/1996), independentemente da legislação ou da relação entre o executivo e o legislativo estaduais, a existência de uma grande disponibilidade de localidades emancipáveis sem a correspondente intensidade relativa de emancipações municipais, não revelam algo atípico, mas uma limitação explanatória da quarta hipótese (sobre a determinação do estoque emancipável). Essa, por sua vez, revela a incapacidade de tratar a probabilidade desigual de emancipação entre distritos urbanos de municípios populosos e distritos rurais de pequenos municípios do interior. Como, diferentemente da maioria das UF's, a maior parte dos distritos de Rio de Janeiro e São Paulo se enquadra no primeiro tipo, de fato, o que ocorre é a existência de uma grande disponibilidade de distritos emancipáveis com baixa probabilidade de emancipação. Porém, como todos são legalmente passíveis de serem emancipados, não seria possível excluir os distritos urbanos do estoque emancipável desses Estados.

Nos dois períodos subseqüentes (1992/1996), quando todos os Estados já haviam regulamentado as emancipações e, portanto, as irregularidades foram sensivelmente reduzidas, as outras características discrepantes continuaram a ser observadas, tanto em relação aos Estados com concentração de distritos urbanos, quanto em relação aos extremos e à volatilidade dos Estados da região Norte. Por outro lado, a comparação entre os três períodos indica elementos relevantes na dinâmica histórica dos surtos emancipacionistas.

\section{Tabela 6 \\ População Mínima ${ }^{(*)}$ Requerida na Emancipação Municipal}

\begin{tabular}{ccc}
\hline UF & $\begin{array}{c}\text { Leis } \\
\text { Complementares }\end{array}$ & População \\
\hline União & LC $01 / 67$ & $10.000\left(^{* *}\right)$ \\
PR & $56 / 91$ & 5.000 \\
RS & $9070-9089 / 90$ & 1.800 \\
SC & $01 / 89$ & 5.000 \\
& $29-33 / 90,34 / 91$ & 1.796 \\
& $37-42 / 91,135 / 95$ & 5.000 \\
ES & $13 / 91$ & 8.600 \\
& $87 / 96,100 / 97$ & Proibido a divisão \\
& & de municípios \\
& & emancipados nos \\
& & últimos 50 anos \\
\hline
\end{tabular}




\begin{tabular}{|c|c|c|}
\hline UF & $\begin{array}{c}\text { Leis } \\
\text { Complementares }\end{array}$ & População \\
\hline \multirow[t]{3}{*}{$\mathrm{MG}$} & $19 / 91$ & 3.000 \\
\hline & $24 / 92$ & 2.000 \\
\hline & $37-39 / 95$ & 2.000 \\
\hline RJ & 59-61/90 & 6.393 \\
\hline SP & 651/90 & 1.000 \\
\hline \multirow[t]{3}{*}{$\mathrm{AL}$} & $01 / 90$ & 7.000 \\
\hline & 06/91 & 7.000 \\
\hline & $11 / 92$ & 5.500 \\
\hline \multirow[t]{2}{*}{$\mathrm{BA}$} & 01/89 & 12.541 \\
\hline & $02 / 90$ & 8.000 \\
\hline \multirow[t]{2}{*}{$\mathrm{CE}$} & $11659 / 89$ & 5.000 \\
\hline & 01/91 & 10.213 \\
\hline MA & $17 / 93$ & 1.000 \\
\hline \multirow[t]{2}{*}{ PB } & $01 / 90$ & 2.000 \\
\hline & $24 / 96$ & 5.000 \\
\hline \multirow[t]{3}{*}{$\mathrm{PE}$} & $01 / 90$ & 10.000 \\
\hline & $14 / 96$ & 10.000 \\
\hline & $15 / 96$ & $\begin{array}{c}\text { Proibido } \\
\text { emancipações } \\
\text { até } 1999\end{array}$ \\
\hline PI & 06/91 & 4.000 \\
\hline $\mathrm{RN}$ & 102/92 & 2.558 \\
\hline SE & $01 / 90$ & 6.000 \\
\hline \multirow[t]{2}{*}{$\mathrm{AC}$} & $23 / 89$ & 2.088 \\
\hline & 35/91 & 1.500 \\
\hline $\mathrm{AM}$ & 07/91 & 965 \\
\hline AP & $01 / 92$ & 948 \\
\hline \multirow[t]{2}{*}{$\mathrm{PA}$} & $01 / 90$ & 5.000 \\
\hline & $27 / 95$ & 10.000 \\
\hline $\mathrm{RO}$ & $31 / 89$ & 6.155 \\
\hline $\mathrm{RR}$ & $02 / 92$ & 2.471 \\
\hline \multirow[t]{3}{*}{ TO } & $01 / 89$ & 2.000 \\
\hline & 05-06/92 & 1.200 \\
\hline & $09 / 95$ & 3.000 \\
\hline \multirow[t]{2}{*}{ GO } & $02 / 90$ & 3.000 \\
\hline & 04/90 & 2.000 \\
\hline \multirow[t]{2}{*}{ MS } & $58 / 91$ & 9.635 \\
\hline & $62 / 91$ & 5.781 \\
\hline \multirow[t]{2}{*}{ MT } & 01/90,08-09/91 & 3.040 \\
\hline & $23 / 92$ & 4.000 \\
\hline
\end{tabular}

Fonte: Lei Complementar federal e estadual, IBGE (Contagem 96, Censo 91).

(*) Quatro Estados utilizam o eleitorado (RS, SP, MG e MA). (**) Menos para os Estados com menos de 2 milhões de hab., quando prevalecia $0,5 \%$ da população. Segundo os dados do "Censo de 1991", a população municipal mínima para essas UF seria: AC (2.088 hab.), AP (1.446 hab.), MS (8.901 hab.), RO (5.663 hab.), RR (1.087 hab.), SE (7.459 hab.) e TO (4.599 hab.).
Primeiro, é possível notar o esgotamento do estoque de localidades emancipáveis nos Estados, seja por mudanças restritivas nas leis complementares estaduais, como nos casos de Santa Catarina, Pará, Tocantins, Ceará e Mato Grosso (Tabela 6), seja pela simples diminuição do mesmo em função da transformação dos distritos em municípios, como em Mato Grosso do Sul, Goiânia, Paraná e, inclusive, Rio Grande do Sul, seja pelo acúmulo dos dois fatores. O inverso também é verdadeiro, com a lei sendo mudada para facilitar as emancipações, expandindo a disponibilidade emancipável, caso, por exemplo, de Mato Grosso, Maranhão e Paraíba.

Segundo, mesmo não sendo possível demonstrar diretamente a partir da relação entre as variáveis, é dedutível a oscilação nas decisões políticas estaduais sobre a emancipação municipal e, portanto, na interação entre executivo e legislativo, tanto pela mudança institucional, quanto pela radical diferença de intensidade emancipacionista nos diferentes períodos num mesmo Estado.

Terceiro, a correlação entre o estoque e as emancipações é menos evidente conforme o processo emancipacionista avança na década de 1990. Conforme cresce a resistência dos atores políticos contrários às emancipações, menor é a capacidade de conversão do estoque emancipável dos Estados em novas municipalidades. Nesse sentido, a determinação fundamental da intensidade emancipacionista estadual encontra-se na interação entre o executivo e o legislativo estaduais e nos mecanismos que definem o processo legislativo, sendo que o tamanho do estoque é tanto resultante dessa interação (na eventual alteração das leis complementares) quanto uma delimitação da potencialidade emancipacionista de cada Estado.

Esses aspectos da dinâmica nos surtos emancipacionistas e nas regulamentações (leis complementares) estaduais indicam que as hipóteses sobre o policy feedback permitiriam ampliar a compreensão dos processos decisórios, sobretudo na análise mais detalhada dos Estados. A percepção das conseqüências dos resultados políticos e das transformações institucionais, pelos atores políticos, motiva o redimensionamento dos interesses dos mesmos a respeito da fragmentação munici- 
pal, sobretudo entre o executivo. Não creio que se trate de um problema de irracionalidade ou de incomensurabilidade nas escolhas dos atores, mas a revisão da racionalidade pela alteração das preferências, ou da ordem de preferências, de alguns atores envolvidos no processo decisório.

Isto pode ser melhor demonstrado na verificação das três primeiras hipóteses com os dados levantados na amostra dos Estados. Segundo a primeira hipótese, a intensidade relativa das emancipações é determinada pela posição política resultante da interação entre o executivo e o legislativo estaduais dentro dos limites dados pela disponibilidade de localidades emancipáveis em cada Estado. Isto é, sem decisões políticas favoráveis, a disponibilidade de localidades emancipáveis não resulta na criação de novos municípios. Como também não basta existir posição favorável, se não houver o que ser emancipado.

Uma posição estadual contrária é descrita quando nenhuma ou proporcionalmente poucas emancipações resultam da oposição do executivo seguida da concordância de uma maioria gover- nista na assembléia. Uma posição é favorável (em graus distintos) quando o executivo apóia ou é indiferente às emancipações; é contrário, mas não possui maioria governista; ou possui maioria, mas esta não segue a posição do executivo (ver a distribuição dos dados na Tabela 7).

A determinação associada das duas variáveis independentes (estoque e interação executivo/legislativo) sobre a intensidade emancipacionista estadual é razoavelmente demonstrada na Bahia, Pernambuco, Rio Grande do Sul e Santa Catarina. Quando não houve oposição do executivo, ou quando esta foi ineficaz, ocorreu sempre grande intensidade de emancipações nesses Estados - como na Bahia (1990), no Rio Grande do Sul (1990, 1992 e 1996) e em Santa Catarina (1990 e 1992). Isso somente não aconteceu quando a disponibilidade de distritos emancipáveis era reduzida - caso de Pernambuco (1990 e 1992) e Santa Catarina (1996). Quando o executivo foi contrário e encontrou apoio parlamentar - Bahia (1992 e 1996) -, nenhum município foi criado, mesmo havendo demandas locais trami-
INTERAÇÃO (EXEC./LEG.) posição política resultante da interação entre o executivo e o legislativo estaduais nas decisões políticas sobre o processo emancipacionista
Tabela 7

\section{Relação entre a Posição Estadual (Executivo/Legislativo) e a Intensidade Emancipacionista Relativa dos Estados (comparada à intensidade média das emancipações nas UF's)}

Quantidade Relativa de emancipações

BAIXA ALTA

(0)

(1)

Executivo contrário
com apoio de maioria
no legislativo
Oposição do
executivo e maioria
arlamentar governista
não confiável
Oposição do
Executivo e coalizão
governista minoritária

Executivo e legislativo favoráveis
(0)

\begin{tabular}{|l|l|}
\hline & \\
\hline BA (1992) & \\
\hline BA (1996) & SC (1992) \\
\hline PE (1996) & RS (1996) \\
SP (1992) & SC (1990) \\
\hline PE (1992) & RS (1992) \\
\hline PE (1990) & \\
SP (1990) & BA (1990) \\
SC (1996) & RS (1990) \\
\hline SP (1996) & \\
\hline
\end{tabular}


tando, apoio de parlamentares e citações na constituição estadual sobre a emancipação de determinados distritos. Esse também foi o caso de Pernambuco (1996), que, no entanto, criou alguns poucos municípios, possivelmente devido à maior fragilidade da coalizão governista.

Além disso, a descrição de variações na posição estadual favorável às emancipações, indicada pela variação no tamanho da coalizão governista e na postura do executivo, demonstra possuir relevância explicativa. Essa relação é identificável pela redução da intensidade emancipacionista conforme aumenta a resistência do executivo. Seja nos Estados com relativa estabilidade na regulamentação estadual (Bahia, Pernambuco e Rio Grande do Sul), seja, como no caso de Santa Catarina, verificável pelo impacto das alterações na legislação complementar nos períodos subseqüentes, facilitando as emancipações em 1990, quando o executivo era minoritário, e dificultando-as em 1991, quando havia maioria governista.

Em São Paulo, como na correlação com a disponibilidade de distritos emancipáveis, também a posição favorável na interação entre o executivo e o legislativo estaduais não determinou uma alta intensidade relativa de emancipações municipais. Portanto, não é possível demonstrar empiricamente a capacidade explicativa da primeira hipótese nesse caso. Contudo, como já mencionei anteriormente, há uma limitação na quarta hipótese, dado que a disponibilidade de distritos emancipáveis não especifica a probabilidade de emancipações. Nesse sentido, os dados sobre o estoque emancipável deste Estado induzem uma alta expectativa emancipacionista que jamais ocorreu, apesar de o legislativo estadual decidir favoravelmente à criação de municípios sem nunca observar a oposição do executivo. Portanto, não foi o processo decisório o fator restritivo ao incremento municipal no Estado. Como em São Paulo a iniciativa da emancipação cabe exclusivamente às lideranças locais e a maior parte do estoque de distritos encontra-se nos municípios muito populosos, sobretudo na capital, possivelmente a falta de estímulos fiscais não motivou o ingresso de demandas emancipacionistas desse tipo na Assembléia Legislativa.
Por outro lado, na relação entre as decisões políticas estaduais e a quantidade de emancipações verifica-se também uma razoável adequação da terceira hipótese: a tendência de autonomia política do legislativo estadual quando as lideranças locais possuem a exclusividade da iniciativa legislativa (proibição de subscrição parlamentar à lei) e a coalizão governista é frágil. Sempre que essas duas condições ocorreram simultaneamente - em Santa Catarina (1992), São Paulo (1992) e Rio Grande do Sul (1996) -, a maioria governista não seguiu a posição contrária do executivo. Quando nenhuma existiu - Bahia (1992 e 1996) -, o executivo não teve dificuldade em sustentar sua posição contrária às emancipações. Porém, na ausência da primeira, Pernambuco (1996), o executivo conseguiu limitar a autonomia parlamentar, mesmo que de forma menos vigorosa.

Isto parece demonstrar que, quanto mais difícil for para associar a lei de criação de município à iniciativa individual de um parlamentar, maior será a possibilidade de ocorrência de deserções na base de sustentação governista. Pelo menos quando essa é frágil. Isto é, quando for formada após o resultado eleitoral, seguindo o que se convencionou chamar regra do situacionismo. Entretanto, sem a restrição desse mecanismo institucional, a maior fragilidade da coalizão governista não seria suficiente para que parte dos parlamentares ignorasse a ameaça de retaliação do executivo. Essa proibição à iniciativa legislativa dos deputados na emancipação transforma a barganha individual (logrolling) entre os parlamentares em uma cooperação onde não há a expectativa de ganhos eleitorais individualizados. Quando os deputados aprovam a esse tipo de lei de emancipação, não aceitando pressão do executivo, respondem a uma iniciativa local referendada pela soberania popular em uma consulta plebiscitária.

Finalmente, há um último aspecto do processo emancipacionista estadual abordado no conjunto de hipóteses explicativas, mas vinculado a um processo decisório distinto do anterior: a dinâmica na regulamentação estadual da divisão municipal. A segunda hipótese sustenta que a produção/alteração de leis complementares estaduais, bem como sua orientação normativa, depende de como o tamanho 


\section{Tabela 8}

\section{Relação entre a Posição Estadual (Executivo/Legislativo), o Tipo de Coalizão de Apoio ao Executivo no Parlamento( ${ }^{(*)}$ e a Dinâmica da regulamentação Estadual (1989-1996)}

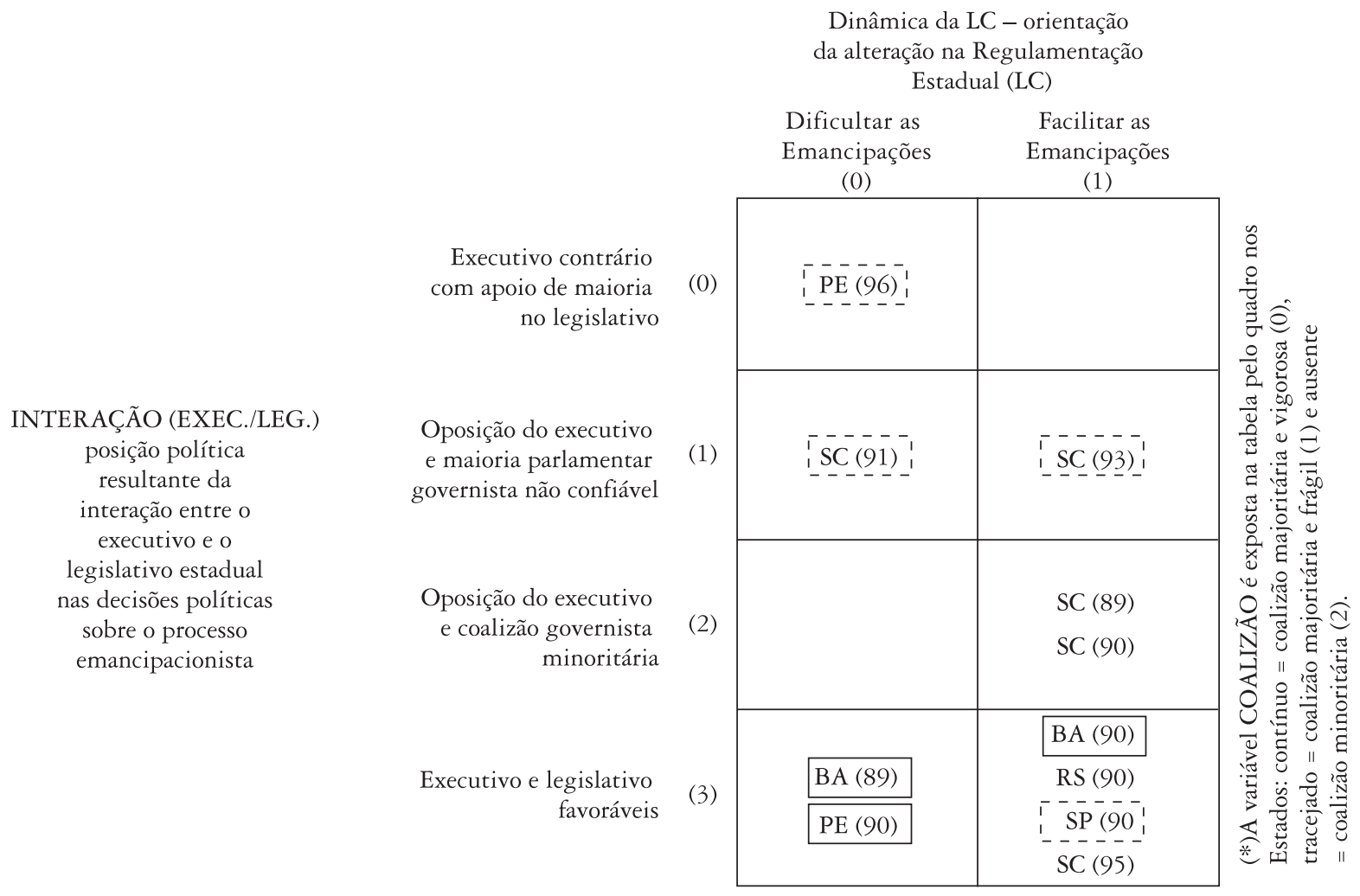

e a consistência da coalizão governista na assembléia determinam o equilíbrio de forças entre $\mathrm{O}$ executivo e o legislativo estaduais (Tabela 8). A estabilidade ou a mudança dessas instituições desempenha um papel fundamental na potencialidade emancipacionista dos Estados pela definição da disponibilidade de localidades emancipáveis. Como é necessário a maioria absoluta da assembléia para aprovar a regulamentação, a alteração na LC (para restringir ou facilitar as emancipações) exige uma recomposição da posição estadual sobre a criação de municípios e um grande investimento do poder que toma a iniciativa na alteração, sobretudo quando não há coincidência entre a posição do executivo e da maioria parlamentar sobre o teor da mudança.

$\mathrm{Na}$ amostra investigada, houve dois casos em que uma única lei complementar foi editada após a transferência constitucional da competência so- bre a regulamentação aos Estados. No Rio Grande do Sul e em São Paulo, a primeira lei foi editada em 1990 com critérios extremamente permissivos, comparada à LC federal 01/67. Em ambos a iniciativa legislativa partiu da assembléia em situações que havia uma posição estadual favorável às emancipações nos dois poderes, sendo que o executivo não possuía condições (coalizão governista majoritária) ou simplesmente não desejava definir critérios mais rigorosos. No RS, o executivo era minoritário e, em SP, a coalizão governista foi formada por negociações posteriores à eleição.

Nos períodos seguintes de emancipações, o executivo dos dois Estados opôs-se à criação de novos municípios, mas a ausência de maioria sólida não permitiu que a regulamentação fosse alterada para restringir as emancipações. Isso foi muito mais claro no Rio Grande do Sul, onde as 
propostas de lei complementar do executivo foram sistematicamente arquivadas. A estabilidade institucional, tanto neste Estado quanto em São Paulo, resultou da incapacidade do executivo (com apoio frágil ou minoritário) em impor alterações restritivas e da preferência da maioria dos deputados em manter o status quo permissivo à criação de municípios.

Em Santa Catarina, onde houve sucessivas alterações na LC, também é possível demonstrar a capacidade explicativa dessa hipótese. A primeira edição da regulamentação estadual foi mais permissiva do que a lei federal, mas como produzia um estoque limitado de localidades emancipáveis, os legisladores estaduais alteraram a LC ampliando a permissividade das exigências legais. Apesar da oposição do executivo, sua base de apoio minoritária na assembléia tornou possível a sucessiva facilitação das emancipações.

No período seguinte, após as eleições estaduais de 1990, por iniciativa do executivo, a lei foi novamente alterada, só que, seguindo a oposição do governador às emancipações, num sentido restritivo. No entanto, apesar de conseguir aprovar a regulamentação, esta foi continuamente objeto de casuísmos legais que isentaram todas as emancipações de seus critérios mais rígidos. Uma coalizão majoritária frágil explicaria as contínuas barganhas entre o executivo e o legislativo, que beneficiaram a posição favorável à criação de municípios. Na última alteração da LC, na legislatura seguinte, os parlamentares novamente facilitaram a emancipação municipal, que nunca havia sido efetivamente dificultada. Essa última mudança não teve a oposição do executivo que, naquele momento, era sustentado por um apoio minoritário na assembléia.

$\mathrm{Na}$ Bahia e em Pernambuco as alterações da lei sempre ocorreram diante de coalizões governistas majoritárias no parlamento. Possivelmente, em virtude do controle do executivo sobre a base governista, em ambos os estados a primeira edição da lei definiu critérios tão ou mais rígidos que a LC federal 01/67. Na Bahia, onde houve logo em seguida uma posterior facilitação, essa continuou a restringir a disponibilidade de localidades emancipáveis de forma semelhante à LC federal.
Em Pernambuco, a única alteração ocorreu para dificultar ainda mais as emancipações. Possivelmente, como naquele momento o executivo era apoiado por uma base majoritária (mas frágil), o governador, apesar de sua oposição manifesta às emancipações, teve de barganhar com o legislativo, aceitando a criação de alguns municípios em troca da aprovação de uma lei complementar que proibisse novas emancipações por quatro anos. Essa estratégia permitiu ao executivo evitar que os legisladores pudessem ser tentados a, num momento decisório seguinte, desertar da base de apoio e aprovar a criação de novos municípios. Na Bahia, por outro lado, a existência de uma sólida e confiável coalizão governista, em todas as legislaturas da década de 1990, tornou desnecessário inovações legais para restringir as emancipações quando o executivo se opunha à criação de novos municípios.

Em todos os Estados da amostra foi possível constatar uma razoável relação entre o tamanho/tipo da maioria governista e o sentido da mudança institucional: facilitação das emancipações quando havia uma coalizão governista minoritária no parlamento estadual; dependente da posição do executivo quando existia um apoio majoritário; e barganhas sobre os resultados quando esse apoio era frágil. Contudo, a capacidade explicativa das hipóteses levantadas devem ser tratadas com uma certa ressalva, devido à limitação de seu conteúdo à amostra e do caráter qualitativo dos valores atribuídos às variáveis explicativas.

\section{Conclusão}

A investigação do processo emancipacionista indica que a intensa divisão municipal brasileira só foi possível devido ao novo arranjo institucional resultante da Constituição de 1988. Em conjunto, vários mecanismos promoveram as bases favoráveis à multiplicação de municípios: a consolidação da descentralização fiscal estimulou as demandas locais pela emancipação de pequenas localidades do interior; a transferência da regulamentação das exigências mínimas às emancipações municipais para o nível estadual, num momento em que os 
recursos do FPM eram divididos nacionalmente e que democratização e descentralização eram tratados ideologicamente como sinônimos, favoreceu, na relação entre os atores políticos estaduais (executivo e legislativo), a posição que desejava produzir leis mais permissivas à criação de municípios, ampliando a disponibilidade de localidades emancipáveis; os procedimentos necessários à promulgação das leis de criação de municípios atribuíram um papel central aos legisladores estaduais que, em virtude de suas expectativas eleitorais, aprovaram a maior parte das demandas locais emancipacionistas.

Além disso, o estudo comparativo entre os Estados demonstrou que a intensidade emancipacionista possui uma variação, na maior parte dos Estados, determinada conforme: a disponibilidade de localidades emancipáveis, a posição resultante da relação de forças entre o executivo e o legislativo estaduais e a presença de mecanismos institucionais que favoreceram a autonomia do legislativo. Isto é, somente o esgotamento da real capacidade emancipacionista estadual, a oposição de um executivo com coalizão majoritária (solidamente apoiado) e/ou a ausência de restrições institucionais ao clientelismo (falta de incentivo à cooperação parlamentar), diante da manutenção dos estímulos fiscais aos eleitores e lideranças dos pequenos municípios e das expectativas futuras dos deputados quanto a sua carreira política, foram capazes de interromper os surtos emancipacionistas nos Estados.

Contudo, como historicamente a oscilação entre coalizões governistas majoritárias e minoritárias nos Estados geraram, eventualmente, mecanismos permissivos à criação de municípios (por meio de leis complementares), manteve-se constante um alto índice de emancipações no Brasil. Isto é, a interrupção desse processo em um Estado (pelo esgotamento da disponibilidade emancipável ou por posições políticas contrárias) foi, normalmente, seguida de novos surtos emancipacionistas em outra unidade da federação (pela alteração da LC e/ou por um novo equilíbrio entre o executivo e o legislativo favorável às emancipações). Em virtude desse fato, como na ditadura militar, o governo federal voltou a intervir no processo para cessar a criação de novos municípios.
Sem a necessidade de alteração do regime político, a recentralização das regras (emenda 15/96) alterou $\mathrm{O}$ arranjo institucional que favorecia as emancipações municipais.

No entanto, como a maior parte dos estímulos fiscais à criação de municípios foi mantido e as expectativas eleitorais futuras dos parlamentares podem gerar novas decisões favoráveis, é possível que surtos emancipacionistas, mesmo que com intensidade menor, continuem a ocorrer no futuro. Porém, dada as imposições sobre a consulta plebiscitária, as divisões territoriais, provavelmente, deverão ser todas restritas a pequenos e micro municípios do interior (os mais frágeis e dependentes do FPM), exatamente a situação menos desejada pelo ator político responsável pela formulação da emenda constitucional - o executivo federal.

\section{NOTAS}

1 Sobre a institucionalidade municipal no federalismo brasileiro, ver Montoro (1974), Mello (1993), Ataliba (1987) e Affonso e Silva (1995).

2 Sobre a relação entre descentralização e democratização no Brasil são interessantes as seguintes referências: Arretche (1996), que aborda a confusão no uso desses termos, polemizando sobre a contínua vinculação entre eles na literatura; este aspecto também está presente nos trabalhos de Tobar (1991) e Uga (1991); o debate sobre a descentralização fiscal e a fragilidade dos municípios em Gomes e Macdowell (2000); a relação entre cidadania e estruturas de governo local em Fischer (1993), que apresenta subsídios sociológicos relevantes ao debate; sobre a heterogeneidade do processo de descentralização das políticas sociais, ver Castro (1991), Arretche (1998) e Almeida (1995); sobre o aumento do poder político dos governantes estaduais, ver Abrúcio (1998); a respeito da ideologia municipalista, ver Melo (1993); e, sobre a defesa das emancipações, são relevantes os trabalhos dos técnicos do Ibam/RJ e Cepam-FPFL/SP, como Bremaeker (1991; 1993), Jacobi (1990; 1991) e Mello (1991; 1992).

3 O alinhamento de posições segue o seguinte padrão: entre os ministros federais e técnicos de institutos ligados à união ou aos Estados é comum a manifestação contrária às emancipações - ver, por exemplo, Gomes e Macdowell (2000), Paraíba (1994), São Paulo (1991) -; já entre políticos regionais (ligados ao legislativo) e ONG's (Ibam/RJ e Cepam/SP), a 
posição emancipacionista é a mais destacada - ver, por exemplo Bremaeker (1991; 1993; 1996), Gasparini (1990), Mello (1991; 1992; 1993), Noronha (1996), Mincarone (1991) e Nunes (1992). Entre os trabalhos acadêmicos há estudos favoráveis, como os de Klering (1991; 1998) e Vizzotto (1997), e alguns que poderiam ser classificados como sem alinhamento ideológico, como Shikida (1998), Mesquita (1992) e Tomio (1998).

4 Sobre os fundamentos da abordagem neo-institucionalista, ver Limongi (1994), Crawford e Ostrom (1995), Immergut (1996), Lowndes (1996), Marques (1997), Hall e Taylor (1997).

5 Este tipo de explicação, que define o regime político como variável independente da intensidade de emancipações municipais, está presente na literatura - em Carvalho (1957), Gasparini (1989) e Mazzilli (1993) - e tem sua melhor construção e argumentação desenvolvida por Gomes e Macdowell (2000). Similarmente, Shikida (1998) relaciona a estrutura do federalismo brasileiro à ocorrência do fenômeno político emancipacionista, por meio do conceito "restrição orçamentária não rígida", no qual as transferências intergovernamentais (FPM), em regimes democráticos, incentivariam os atores a decidir favoravelmente pela emancipação onde fosse possível ampliar a disponibilidade de recursos às localidades emancipadas.

6 Há explicações orientadas por uma abordagem funcionalista, como a de Bremaeker, segundo a qual as emancipações municipais responderiam a "uma lógica extremamente racional" (1991, p. 33). Outra explicação similar é desenvolvida por Mesquita. Utilizando uma abordagem sistêmica, a autora define que as causas últimas das emancipações municipais estariam no processo de modernização (Mesquita, 1992, p. 170). Há, ainda, outras explicações para o fenômeno, como a apresentação de causas institucionais em Mello (1992); as explicações das emancipações pelas motivações dos atores locais (Bremaeker, 1993; Noronha e Cardoso, 1995; Klering, 1991 e 1998); e a hipótese de Abrúcio (1998), sustentando que a multiplicação de municipalidades seria o produto da existência de um "modelo hobbesiano e predatório" na federação brasileira.

7 O caso do município de São João do Polêsine-RS, antigo distrito de Dona Francisca-RS, revela esse tipo de ocorrência. O município, que somou a população de 2583 habitantes na "Contagem de 1996" do IBGE, só conseguiu se emancipar em 1992, por meio dos critérios da Lei complementar estadual 9.070/90. Em 1986 o município já havia pleiteado a emancipação, que foi declarada inconstitucional devido a um recurso julgado pelo STF. Entretanto, no mesmo ano, outros municípios gaúchos foram criados apresentando população aquém da exigida na LC 01/67: 10 mil habitantes. Porém, nenhum desses teve sua emancipação questionada juridicamente (Vizzotto, 1997, p. 70).

8 Isto não significa excluir a possibilidade de alguns atores serem motivados, eventualmente ou sempre, por valores político-ideológicos ou normas sociais, orientando suas escolhas por uma racionalidade não instrumental. Da mesma forma, comportamentos irracionais também poderiam ocorrer durante as decisões presentes no processo emancipacionista. Entretanto, segundo os pressupostos deste trabalho, a conduta egoísta, racional e instrumental é utilizada quando interpreto dedutivamente a motivação dos atores políticos que interagem no processo decisório das emancipações municipais.

9 Utilizando fórmulas sobre o valor de transferências adicionadas aos municípios quando estes se dividem (tendo como variáveis a população do município, a população da localidade emancipanda e as faixas de coeficientes do FPM), Shikida criou um modelo dedutivo que determinaria: 1) haver o interesse local favorável às emancipações sempre que a soma das cotas do FPM gerada pela nova situação seja maior que o FPM do status quo; 2) "[...] a melhor resposta de cada município à ação emancipacionista do outro é - igualmente - adotar a estratégia da emancipação" (1998, pp. 23-30).

10 Na maior parte dos Estados, a regulamentação promulgada após a Constituição de 1988 reproduziu a regra presente na legislação federal anterior (LC 01/1967). Nesses, a iniciativa do processo legal emancipacionista continuou restrita à demanda popular local. No entanto, em alguns Estados (MA, $\mathrm{BA}, \mathrm{RN}, \mathrm{AP}, \mathrm{GO}$ e MS) a nova legislação criou a exigência da subscrição de um parlamentar à iniciativa local, enquanto em outros (PB, PE e AC), os membros do legislativo e do executivo estaduais ganharam o direito de iniciar o processo sem a necessidade de demanda prévia dos eleitores da localidade emancipanda.

11 A noção de "clientelismo eleitoral" é considerada distinta do clientelismo de tipo tradicional, em que as "amarras" entre clientela e patrono, devido a uma situação histórica, econômica e culturalmente arraigadas, são extremamente fortes. No tipo eleitoral, a patronagem por meio da alocação concentrada de recursos públicos está diretamente relacionada ao resultado eleitoral, e a clientela tem o direito, pelo menos, à escolha de qual patrono irá eleger. Dessa forma, o clientelismo eleitoral não é apenas compatível com as regras democráticas e sua instabilidade quanto aos resultados políticos futuros, mas também 
necessita minimamente disso para sua reprodução e legitimidade. Para mais detalhes sobre a relação entre clientelismo e eleições, ver Avelino (1994, p. 228), Castro (1988, pp. 65-68) e Santos (1995).

12 O fisiologismo é tratado aqui como distinto da prática do clientelismo e de sua forma pertinente a este esquema: o clientelismo eleitoral. Como bem define Couto, "o que caracteriza o fisiologismo [nas relações executivo/legislativo] é o fato de que a barganha política ocorre através da transferência de recursos diretamente para o controle dos legisladores, ao passo que o clientelismo se baseia na transferência de recursos do Estado para a base politico-eleitoral dos parlamentares". O fisiologismo é um mecanismo que, num segundo momento, pode servir à atuação clientelista dos parlamentares pela utilização dos recursos que esses têm sob controle (Couto, 1998, pp. 48-49).

13 No Brasil, com exceção do período entre 1967 e 1988 (regime militar) e após 1996 (emenda 15/96), os Estados sempre foram o nível de governo responsável pela regulamentação das emancipações municipais (Barreto, 1971).

14 Os recursos dos fundos estaduais são provenientes da arrecadação de ICMS (6,25\% do total) e a sua distribuição entre os municípios segue critérios estaduais (população, área, atividade econômica etc.). O estímulo desse fundo às emancipações varia conforme os critérios de distribuição e, principalmente, o nível de desenvolvimento econômico estadual. Porém, em nenhuma unidade da federação os valores dos fundos do ICMS superam as transferências fiscais do FPM.

15 Segundo Gomes e Macdowell (2000), em média, os municípios brasileiros com menos de 10.000 habitantes geram menos de $10 \%$ de sua receita por esforços fiscais próprios.

16 A história do FPM começa nos anos de 1940. A Constituição de 1946, no \40 o art. 15, determinou a transferência, "em partes iguais" aos municípios do interior, de 10\% da arrecadação do Imposto de Renda. A Emenda Constitucional n. 5 de 1961 ampliou a participação dos municípios nesse imposto para $15 \%$ e incrementou o fundo com $10 \%$ da receita sobre o imposto de "consumo de mercadorias". O regime militar, por meio da Emenda Constitucional n. 18 de 1965, instituiu uma nova ordem tributária que criou o FPM, diminuindo a participação dos municípios para 10\% do IR e do IPI, além de determinar a forma de aplicação da maior parte desses recursos. Em 1969, por meio da Constituição imposta pela junta militar, o FPM foi reduzido para 5\% do IR e IPI. A partir de meados da década de 1970, a participação do FPM sobre esses tributos foi sendo paulatinamente aumentada, até atingir 22,5\% em 1993, conforme norma estabelecida pela Constituição de 1988 (Barreto, 1971; Brasil, 1988).

17 Essa divisão do FPM é determinada pela Lei federal $5.172(25 / 10 / 1966)$ e pelo Decreto Lei 1.881 (27/08/1981).

18 Haviam dois outros coeficientes $(0,2$ e 0,4$)$ que eram atribuídos a municípios menores. No entanto, estes foram extintos em 1981 (pelo Decreto Lei 1.881), o que ampliou os recursos destinados aos micromunicípios.

19 As cotas estaduais no FPM foram criadas pela Lei Complementar federal 62 (28/12/1989).

20 Certamente alguns parlamentares podem estimular as iniciativas de emancipação das lideranças locais e muitos devem procurar obter o reconhecimento do eleitorado local, manifestando-se publicamente pela criação do município ou vinculando uma decisão favorável à sua atuação parlamentar. Entretanto, isto não retira o papel do mecanismo que atribui a prerrogativa única aos eleitores locais na iniciativa da emancipação, seja para restringir a capacidade de sanção do executivo sobre sua base de apoio, seja para desvincular formalmente a lei de criação de município do conjunto de leis clientelistas aprovadas pelo parlamento.

21 Não foram atribuídos valores a quatro variáveis descritos no diagrama geral das hipóteses. Ao indicador INTERESSES, porque descreve, de forma simplificada, o modelo de expectativas sobre a racionalidade das escolhas dos atores políticos envolvidos no processo decisório. Desta forma, a não ser que exista evidência contrária, será sempre atribuído à maioria dos parlamentares o interesse dominante favorável às emancipações, enquanto o interesse do executivo será dependente, prioritariamente, da percepção desses atores sobre as conseqüências do processo emancipacionista, o que somente é verificável na amostra de Estados (BA, PE, RS, SC e SP) em que o processo emancipacionista foi investigado com maior detalhamento. Já a variável LOCALIDADES é um indicador quantitativo contínuo da disponibilidade de distritos, vilas ou lugarejos nos Estados, enquanto as outras duas variáveis (MUDANÇA INSTITUCIONAL e CONSEQÜÊNCIAS) expressam o feedback entre os resultados políticos (dinâmica institucional e percepção das conseqüência pelos atores) e suas causas (mecanismos institucionais e preferências dos atores políticos), envolvendo o processo emancipacionista na historicidade política. Como tal, essas variáveis, bem como as hipóteses a elas associadas, complementam a explicação do fenômeno. Os indicadores derivados dessas variáveis serviriam à interpretação histórica do processo emancipacionista, sobretudo 
nos estudos de caso que possam aprofundar a investigação da criação de municípios, o que não é o objetivo deste texto.

22 Os Estados da amostra foram selecionados, em 1998, no início do levantamento empírico que forneceu os dados para a minha tese de doutorado, pelo cruzamento de duas variáveis: intensidade emancipacionista relativa (abaixo/acima da média nacional) e dinâmica da legislação complementar estadual (facilitar/manter o status quo/dificultar as emancipações). Disto resultou seis grupos de Estados, sendo que em cada um foi selecionado uma unidade para o levantamento empírico (realizado entre 1988 e 1990), com exceção da combinação "abaixo da média/LC alterada para facilitar as emancipações", visto que não havia informações de nenhum Estado que se enquadrasse nessa situação.

23 Na relação, somente os distritos municipais (registrados pelo IBGE) foram definidos como localidades, visto que esse é o único dado disponível. No entanto, na maioria dos Estados, as leis não exigem que a localidade emancipanda seja um distrito legalmente constituído.

\section{BIBLIOGRAFIA}

ABRÚCIO, Fernando. (1998), Os barões da federação. São Paulo, Hucitec/DCP-USP.

AFFONSO, Rui de Britto \& SILVA, Pedro. (1995), $A$ federação em perspectiva. São Paulo, Fundap.

ALMEIDA, Maria H. T. (1995), "Federalismo e políticas sociais". RBCS, 28: 88-108.

ARRETCHE, Marta. (1996), "Mitos da descentralização - mais democracia e eficiência nas políticas públicas?". RBCS, 11 (31): 44-66.

(1998), O processo de descentralização das politicas sociais no Brasil e seus determinantes. Tese de doutorado, IFCH/Unicamp, datilo.

ATALIBA, Geraldo. (1987), "Regime federativo", in R. Faoro et al., Constituição e constituinte, São Paulo, Editora Revista dos Tribunais.

AVELINO, George Filho. (1994), "Clientelismo e política no Brasil - revisitando velhos problemas". Novos Estudos Cebrap, 38.
AZZONI, Carlos Roberto \& ISAI, João Yo. (1993), "Censo demográfico, novos municípios e reforma tributária: impacto sobre as finanças municipais". Revista de Administração Pública, 27 (3): 50-61.

BARRERA, Aglas Watson \& ROARELLI, Maria Liz de Medeiros. (1995), "Relações fiscais intergovernamentais", in R. B. Affonso \& P. L. B. Silva (orgs.), Reforma tributária e federação, São Paulo, Ed. Unesp.

BARRETO, Carlos Eduardo (org.). (1971), Constituições do Brasil. São Paulo, Edições Saraiva.

BRASIL. (1988), Constituição: República Federativa do Brasil. Brasília, Senado Federal.

BREMAEKER, François E. J. (1991), Os novos municipios brasileiros instalados entre 1980 e 1990. Rio de Janeiro, Ibam.

(1993), "Os novos municípios: surgimento, problemas e solução". Revista de Administração Municipal, 40 (206): 88-99.

(1996), "Limites à criação de novos municípios: a emenda constitucional. n. 15". Revista de Administração Municipal, 43, 219:118-128.

CARDOSO, Dária \& PROSERPIO, Renata. (1993), "Quadro territorial do Estado da Bahia: evolução e situação atual”. Bahia Análise E Dados, 2 (4): 96-100.

CARVALHO, Orlando M. (1957), A multiplicação dos municípios em Minas Gerais. Rio de Janeiro, Ibam.

CASTRO, Maria Helena Guimarães de. (1988), "Governo local, processo político e equipamentos sociais: um balanço bibliográfiCO". BIB, 25.

(1991), "Descentralização e política social no Estado de São Paulo - tendências e perspectivas". Revista Cepam, II, 1.

COUTO, Cláudio G. (1998), "Negociação, decisão e governo: padrões interativos na relação executivo-legislativo e o caso paulistano", in R. C. Andrade (org.), Processo de governo no município e no Estado, São Paulo, Edusp. 
CRAWFORD, Sue \& OSTROM, Elinor. (1995), "A grammar of institutions". American Political Science Review, 89 (3): 582-600.

DUCHACEK, Ivo D. (1988), "State constitucional law in comparative perspective". Annals AAPSS, 496: 128-139.

ELSTER, Jon. (1994), Peças e engrenagens das Ciências Sociais. Rio de Janeiro, RelumeDumará.

FIGUEIREDO, Argelina Cheibub \& LIMONGI, Fernando. (1994), "O processo legislativo e a produção legal no congresso pós-constituinte". Novos Estudos, 38: 24-37.

(1999), Executivo e legislativo na nova ordem constitucional. Rio de Janeiro, Ed. da FGV.

FISCHER, Tânia (org.). (1993), Poder local-governo e cidadania. Rio de Janeiro, Ed. da FGV.

GASPARINI, Diógenes. (1989), Criação de municípios na Constituição Estadual. São Paulo, CEPAM, mimeo.

(1990), "A criação de municípios em São Paulo". Revista CEPAM, I, 2.

GOMES, Gustavo Maia \& MacDOWELL, Maria Cristina. (2000), Descentralização politica, federalismo fiscal e criação de municípios. Brasília, Ipea, (Texto para Discussão n. 706).

HALL, Peter \& TAYLOR, Rosemary. (1997), "La Science Politique et les trois néo-institutionnalismes". Revue Française Science Politique, 47, (3-4): 469-496.

IMMERGUT, Ellen. (1996), The normative roots of the new institutionalism: historical institutionalism and comparative policy studies. Baden-Baden, mimeo.

JACOBI, Pedro. (1990), "Descentralização municipal”. Revista CEPAM, I, 3.

(1991), "Os municípios e a participação: desafios e alternativas". Revista de Administração Municipal, 38 (198): 32-38.
KLERING, Luís Roque. (1991), "Desempenho dos novos municípios - emancipações políticas do RS na década de 80: razões, histórico e diretrizes", in M. Mincarone, Emancipação: liberdade para prosperar, Porto Alegre, Assembléia Legislativa.

(1998), "Experiências recentes em municípios brasileiros - os novos municípios e as conquistas da autonomia", in R. Fachin \& A. Chanlat (org.), Governo municipal na América Latina: inovações e perplexidades, Porto Alegre, Sulina/Ed. da Universidade/UFRGS.

LEVI, Margaret. (1991), "Uma lógica da mudança institucional”. Dados, 34 (1): 79-99.

LIMONGI, Fernando. (1994), "O novo institucionalismo e os estudos legislativos". BIB, 37.

LOWNDES, Vivien. (1996), "Varieties of new institutionalism: a critical appraisal". Public Administration, 74:181-197.

MARQUES, Eduardo C. (1997), "Notas críticas à literatura sobre Estado, políticas estatais e atores políticos". $B I B, 43$.

MAZZILLI, Antônio C. (1993), O processo de emancipação dos municípios na Assembléia e suas conseqüências. Belo Horizonte, Encontro dos Municípios Mineiros, mimeo.

MELLO, Diogo Lourdello de. (1991), "Descentralização, papel dos governos locais no processo de desenvolvimento nacional e recursos financeiros necessários para que os governos locais possam cumprir seu papel". Revista de Administração Pública, 25 (4): 199-217.

(1992), "A multiplicação dos municípios no Brasil". Revista de Administração Municipal, 39 (203): 23-38.

(1993), "O governo municipal brasileiro: uma visão comparativa com outros países". Revista de Administração Pública, 27 (4): 36-53.

MELO, Marcus André B. C. de. (1993), "Municipalismo, nation building e a modernização do Estado no Brasil". RBCS, 23. 
MESQUITA, Zilá. (1992), "Emancipações no RS: alguns elementos para reflexão". Análise Conjuntural, 20 (3): 169-184.

MINCARONE, Marcelo. (1991), Emancipação: liberdade para prosperar. Porto Alegre, Assembléia Legislativa.

MONTORO, Eugenio Augusto Franco. (1974), A organização do município na federação brasileira. Tese de doutorado, PUC/SP, datilo.

NORONHA, Rudolf de \& CARDOSO, Elizabeth D. (1995), "Emancipações municipais: como ficam os municípios de origem?". Revista de Administração Municipal, 42 (214): 67-80.

NORONHA, Rudolf de. (1996), "Criação de novos municípios: o processo ameaçado". Revista de Administração Municipal, 219.

NUNES, Jorge C. P. (1992), Criação de municípios no novo Estado do Rio de Janeiro. Rio de Janeiro, Alerj.

ORLOFF, Ann Shola. (1993), A comparative analysis of Britain, Canada, and the United States, 1880-1940. Wisconsin, The University of Wisconsin Press.

PARAÍBA. SEPLAN. Instituto de Desenvolvimento Municipal e Estadual da Paraíba. (1994), A criação de novos municípios e sua repercussão na distribuição do FPM. João Pessoa, Seplan/Ideme.

RIBEIRO, Carlos A. C. (1993), "Crise fiscal em municípios: uma discussão teórica a cerca de suas causas, indicadores e instrumentos". Planejamento e Políticas Públicas, 9.

SANTOS, Fabiano Guilherme M. (1995), "Microfundamentos do clientelismo político no Brasil: 1959-1963". Dados, 38, 3:459-496.

SANTOS, Fabiano \& PATRÍCIO, Inês. (1996), Um modelo de produção legislativa em diferentes contextos institucionais. Caxambu, $\mathrm{XX}$ Anpocs, mimeo.

SANTOS, Maria Helena de Castro. (1997), "Governabilidade, governança e democracia: criação de capacidade governativa e rela- ções executivo-legislativo no Brasil pósconstituinte". Dados, 40 (3): 335-376.

SÃO PAULO. Secretaria do Governo/Secretaria de Planejamento e Gestão. (1991), Estudo de viabilidade de emancipação dos Distritos. São Paulo, mimeo.

SEI. Superintendência de Estudos Econômicos e Sociais da Bahia. (1998), Classificação dos municípios baianos. Salvador, SEI.

SHIKIDA, Cláudio Djissey. (1998), Emancipação de municipios em Minas Gerais (1995): uma abordagem Novo-Institucionalista e de Escolha Pública. Dissertação de mestrado, FEA/USP, datilo.

TAVARES, Iris. (1997), "O município brasileiro: sua evolução histórico-cultural”. R. Dir. Adm., 209: 169-187.

THELEN, Kathleen \& STEINMO, Sven. (1992), "Historical institutionalism in comparative politics", in S. Steinmo et al. (eds.), Structuring politics: historical institutionalism in comparative analysis, Cambridge University Press.

TOBAR, Federico. (1991), "O conceito de descentralização: usos e abusos". Planejamento e Politicas Públicas, 5.

TOMIO, Fabricio Ricardo de Limas. (1998), "Explosão municipal: notas de uma pesquisa", in J. R. A. Flôres \& M. O. Natividade (orgs.), Politica, cultura \& sociedade, Santa Maria, UFSM/PRE/DSP.

TSEBELIS, George. (1997), "Decision making in political systems: veto players in presidentialism, parliamentarism, multicameralism and multipartyism". British Journal of Political Science, 25: 289-325.

UGA, Maria Alicia D. (1991), "Descentralização e democracia: o outro lado da moeda". Planejamento e Políticas Públicas, 5.

VIZZOTTO, Assis Roque. (1997), A emancipação e divisão política de Faxinal do Soturno, causas e conseqüências. Dissertação de mestrado, UFSM, datilo. 


\section{A CRIAÇÃO DE MUNICÍPIOS APÓS A CONSTITUUIÇÃO DE 1988}

Fabricio Ricardo de Limas Tomio

\section{Palavras-Chave}

Relações executivo-legislativo; Emancipações municipais; Federação; Instituições políticas; Processo decisório estadual.

Este artigo analisa o processo decisório estadual e o arranjo institucional (transferências fiscais, competências dos entes federativos e procedimentos legislativos) que geraram, entre 1988 e 2000, 1.438 novos municípios no Brasil (25\% do total). A abordagem enfatiza o papel dos mecanismos institucionais na orientação das estratégias dos atores e na determinação dos resultados políticos. A interpretação e os dados empíricos fundamentam duas hipóteses explicativas: 1) o processo emancipacionista é resultante dos mecanismos (arranjo institucional) que moldaram um ambiente favorável às decisões de criação de municípios; e 2) a variação estadual resultaria: (a) de como a regulamentação alterou a disponibilidade de localidades emancipáveis; (b) da natureza da interação entre o executivo e o legislativo; (c) do tamanho/tipo da coalizão governista e (d) da existência de dispositivos legais (sobre a iniciativa e a tramitação da proposição) que ampliaram a autonomia do legislativo estadual nesse processo decisório.

\section{THE CREATION OF MUNICIPALITIES AFTER THE 1988 CONSTITUTION}

Fabricio Ricardo de Limas Tomio

\section{Keywords}

Executive/legislative interaction: New municipalities; federation; Political institutions; State decision process.

This article examines the decision process in states governments and the political-institutional context (intergovernmental flow of funds, competences of governmental entities in federation, legislatives proceedings) that produced, between 1988-2000, the proliferation of 1,438 new municipalities in Brazil (25\% from total of municipalities). The approach emphasizes the role of institutional mechanisms on direction of actors' political strategies and determination of politics outcomes. The interpretation and empiric research produced the following hypothesis to explain this political process: 1) the new municipalities' proliferation process is resultant from mechanisms (institutional arrangement) which shaped a favourable situation to decisions that created the municipalities; and 2) the state variation in process shall have resulted from: (a) how the regulations changed the available quantity of localities/towns to be able to turn municipalities, (b) kind of interaction between executive/ legislative, (c) size/type of government coalition in state parliament and (d) existence of legal provision (about initiative and procedure of legislative proposition in the state parliament) which enlarged the autonomy of state parliament on decision process to create municipalities.
LA CRÉATION DE COMMUNES APRÈS LA CONSTITUTION DE 1988

Fabricio Ricardo de Limas Tomio

\section{Mots-clés}

Intéraction exécutif/législatif; Nouvelles municipalités; Féderation; Institutions politiques; Processus de décision régionales.

Cet article analyse le processus de décision régional (au niveau des États de la Fédération) et l'arrangement institutionnel (transferts fiscaux, compétences des organes fédératifs et procédures législatives) engendré entre 1988 et 2000 par 1.438 nouvelles communes au Brésil (1/4 du total des communes existantes). Notre approche met l'accent sur le rôle des mécanismes institutionnels dans l'orientation des stratégies des acteurs et dans la détermination des résultats politiques. L'interprétation et les données empiriques permettent l'élaboration des hypothèses explicatives suivantes: 1) le processus d'émancipation résulte de mécanismes (arrangement institutionnel) qui ont formé un environnement favorable aux décisions qui ont créé les communes; et 2) les variations régionales résulteraient: (a) de la manière dont la réglementation a modifié la possibilité de localités émancipables, (b) de la nature de l'interaction exécutif/législatif, (c) de la taille/type de coalition au sein du gouvernement, et; (d) de l'existence de dispositifs légaux (par l'initiative et le cheminement bureaucratique de la proposition) qui ont augmenté l'autonomie du législatif régional dans ce processus décisionnel. 